\title{
A Physical Model Study of the North Shore Wastewater Treatment Plant Pump Station
}

\author{
By \\ Maryam Shahab \\ M.Sc., University of Science and Culture, Tehran, 2017 \\ A major research project \\ presented to Ryerson University \\ in partial fulfillment of the \\ requirements for the degree of \\ Master of Engineering \\ in the program of \\ Civil Engineering
}

Toronto, Ontario, Canada, 2020

(c) Maryam Shahab, 2020 


\title{
A Physical Model Study of the North Shore Wastewater Treatment Plant Pump
}

\author{
Station \\ Master of Engineering 2020 \\ Maryam Shahab \\ Civil Engineering \\ Ryerson University
}

\begin{abstract}
Large scale water pumps with bell mouth intakes have been broadly used by municipal wastewater services to move sewage to wastewater treatment plants. Swirling of the flow when entering the suction bell of the pump intake can cause free-surface and/or sub-surface vortices, resulting in poor pump operation. In order to properly design, the wet well of sewage pump station both physical and numerical models are used to analyze the flow condition entering the pump intake and the associated flow pattern and potential vortex formation. In cooperation with WSP Canada Ltd., a physical modelling study of the First Narrows Sewage Pumping Station was conducted by the Ryerson research team at Ryerson University’s Centre of Urban Innovation Laboratory. During the physical model testing, uneven flow distributions including vortices were observed at the intake chamber under three pump-working conditions. To achieve an even flow distribution with minimal vortices, alternative slot designs at the entrance of the chamber were analyzed. Additionally, a tapered design of the suction bell intake was tested for potential vortex formation. The results showed that a reduced area of the entrance slot could distribute the inflow evenly in the chamber. Moreover, no vortex formation around the tapered suction bell was found under (a) a low flow condition of $10 \mathrm{l} / \mathrm{s}$ at a water level $-5.10 \mathrm{~m}$ below datum and (b) a cleaning cycle scenario of $16 \mathrm{l} / \mathrm{s}$ at a water level $-4.9 \mathrm{~m}$ below the datum. However, there was observed water rotations at the backwall side. For tight and intense water rotations, it might cause vortex formation. This study has provided design changes that can smooth the flow and reduce vortices at the bell mouth intakes of the pump intake chamber.
\end{abstract}




\section{Acknowledgments}

I would like to express my sincere gratitude to my supervisor, Dr. James Li, for his continuous encouragement and support in the development of this research.

Many thanks to Jean-Luc Daviau and his team members at WSP Canada Ltd. for their respectful advice and collaboration at Ryerson's CUI laboratory and the suggested improvement of the research report.

I am grateful to Robin Luong at the Ryerson Civil Engineering Laboratory, for his help and support. Also, I would like to acknowledge Jimmy Luc, a laboratory assistant who helped me at the lab.

I would also like to thank Dr. Darko Joksimovic for serving as examining committee member.

Finally, I am beyond thankful to my family who have always supported me with their love and enthusiasm. 


\section{Table of Contents}

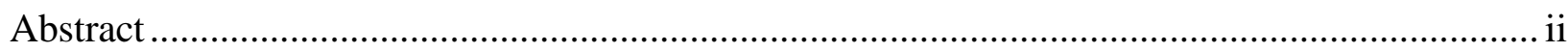

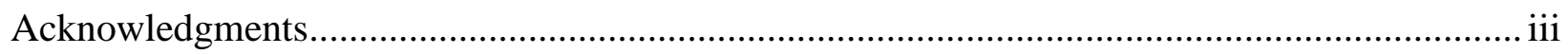

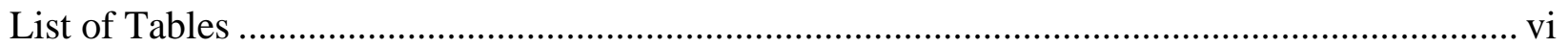

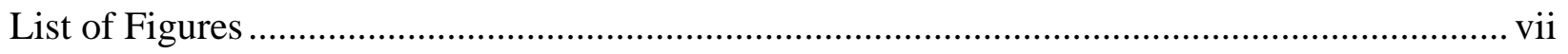

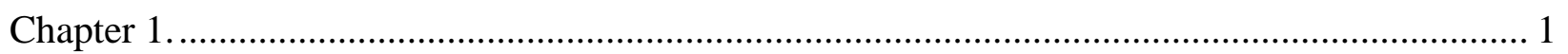

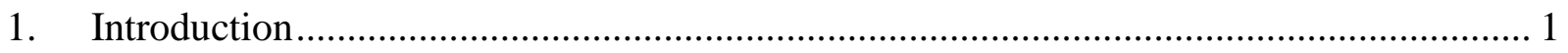

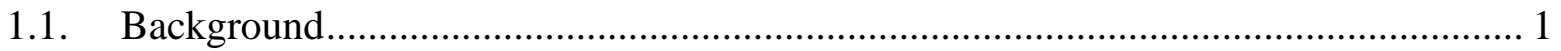

1.2. Hydraulic Issues in Wastewater Pump Intake ............................................................ 1

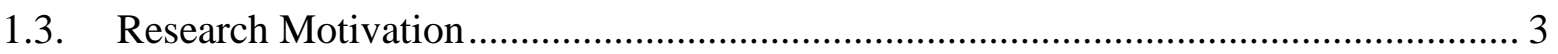

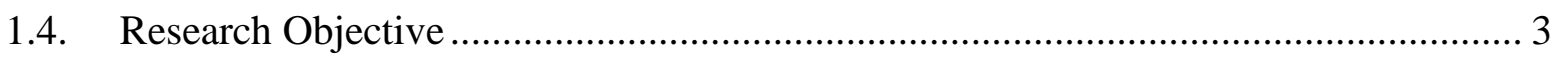

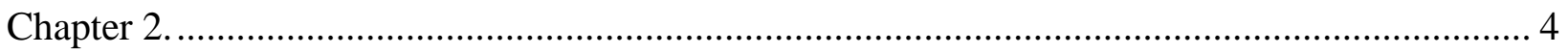

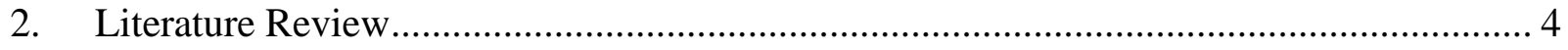

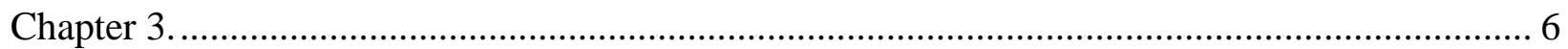

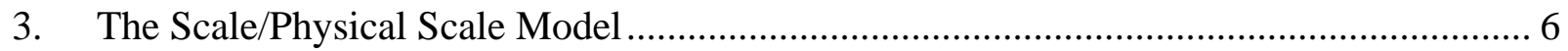

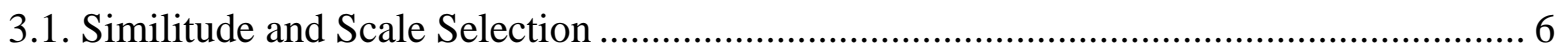

3.2. Physical Model Study Purpose ......................................................................................... 8

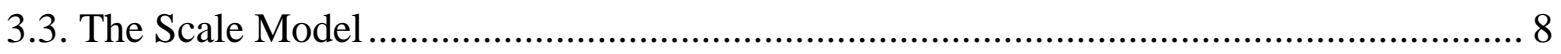

3.4. Instrumentation and Measuring Techniques............................................................ 12

3.5. Scale Model Construction ..................................................................................... 12

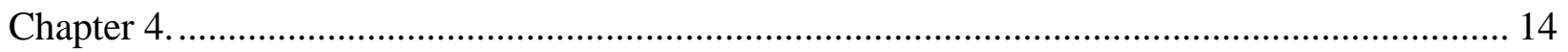

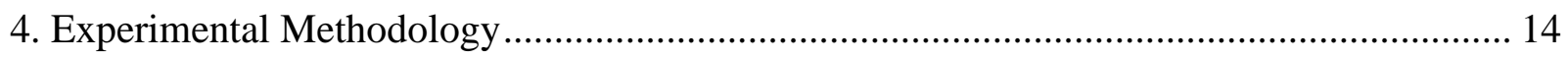

4.1. General Description of the Experiment ........................................................................ 14

4.2. Procedure of Testing to Achieve Even Water Distribution in the Chamber ................... 14

4.3. Procedure of Testing to Analyze the Tapered Bell Design .............................................. 17

4.4. Experimental Data Analysis ................................................................................. 19

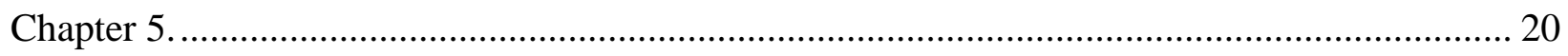

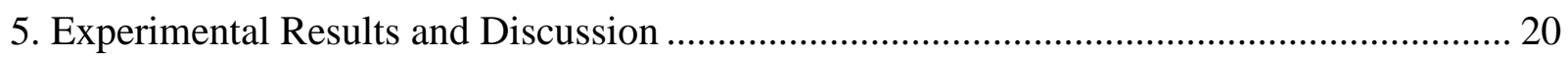

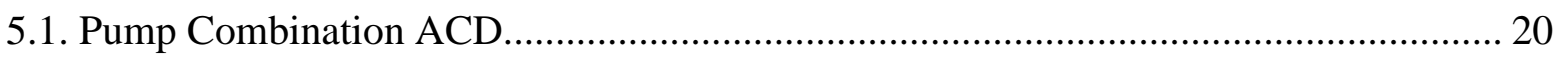

5.1.1. Procedure of Finding the Required Size for Opening Slot A .................................. 20 


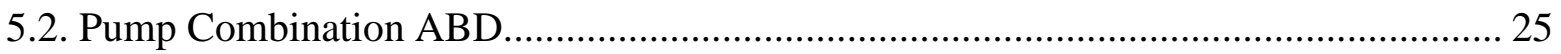

5.2.1. The Procedure of Finding the Required Size of Opening B ................................... 25

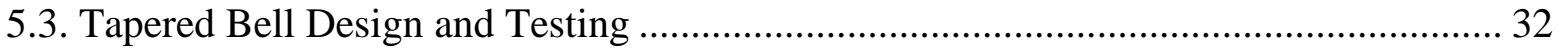

5.3.1. Pump A Working Under the Low Flow Condition.................................................. 32

5.3.2. Pump A Working Under the Cleaning Cycle Scenario ............................................. 33

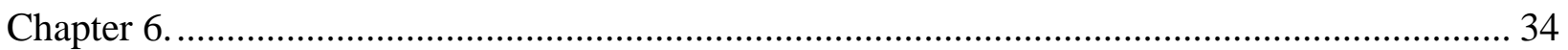

6. Conclusions and Recommendations................................................................................. 34

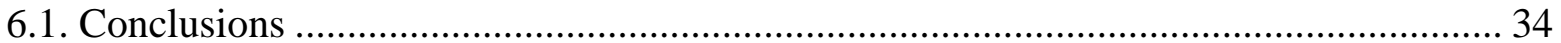

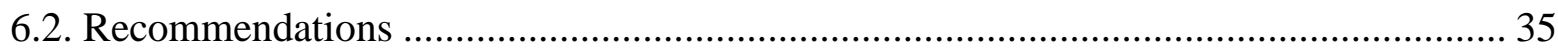

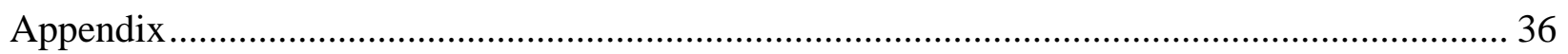

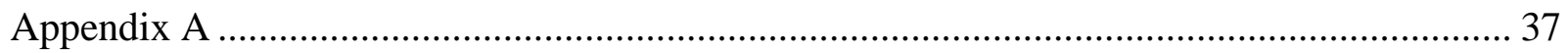

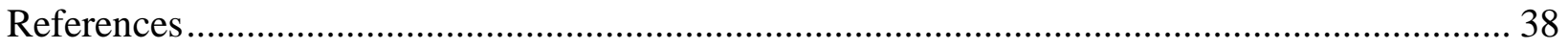




\section{List of Tables}

Table 1. Experimental measurements for the pumps ACD combination with a flow of $10 \mathrm{l} / \mathrm{s}$ for at each pump 21

Table 2. Experimental measurements by covering $40 \%$ of the opening A for the pumps ACD

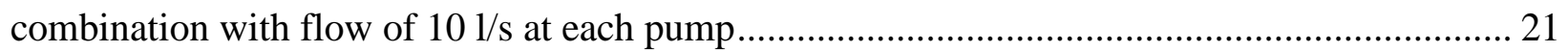

Table 3. Experimental measurements by covering 35\% of the opening A for the pumps ACD

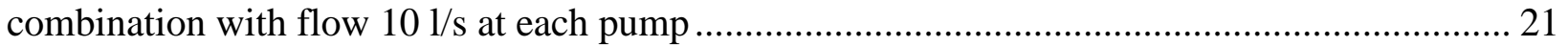

Table 4. Estimation of discharge coefficient of Openings A, C, and D for the pumps ACD combination at a flow of $10 \mathrm{l} / \mathrm{s}$ and 35\% covering of Opening A

Table 5. Experimental measurements of the pump ABD combination at a flow $10 \mathrm{l} / \mathrm{s}$ for each pump

Table 6. Experimental measurements of the pump ABD combination by blocking 35\% of Opening

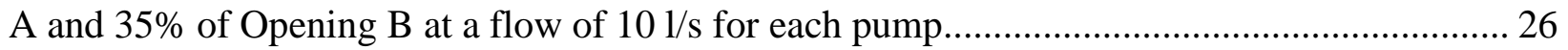

Table 7. Experimental measurements of the pump ABD combination by blocking 35\% of Opening

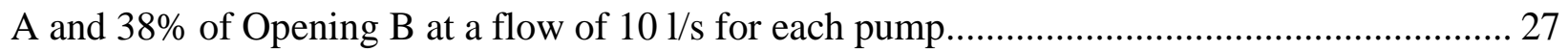

Table 8. Experimental measurements of the pumps ABD combination by blocking 35\% of Opening $\mathrm{A}$ and $40 \%$ of Opening $\mathrm{B}$ at a flow of $10 \mathrm{l} / \mathrm{s}$ for each pump ...................................... 27

Table 9. Experimental measurements of the pumps ABD combination by blocking 35\% of

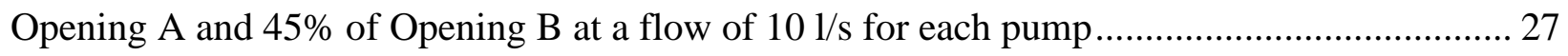

Table 10. Estimation of coefficient of discharge for Openings A, B, and D for the pump ABD combination at a flow of $10 \mathrm{l} / \mathrm{s}$ with Opening A covered by 35\% and Opening B covered by 45\%

Table 11. A summary of the estimated coefficient of discharge for opening slots A and D....... 31 


\section{List of Figures}

Figure 1. Typical water pump intake: (a) plan view; (b) Section A-A (adopted from Li et al., 2004)

Figure 2. A tridimensional (3D) view of the physical model of the First Narrows Sewage Pump Station wet well and location of the instruments (Shore et al., 2018) ...................................... 9

Figure 3. Side view of the physical model and dimensions (Shore et al., 2018) ....................... 10

Figure 4. Plan view of the physical model and dimensions (Shore et al., 2018) ........................ 10

Figure 5. "Translucent and opaque components for flow visualization (Green is translucent and

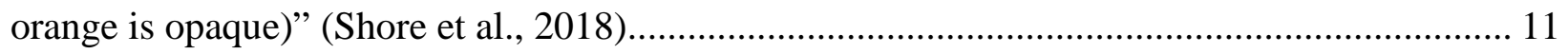

Figure 6. An upstream view of the constructed physical model at the Ryerson laboratory ......... 13

Figure 7. A downstream view of the constructed physical model at the Ryerson laboratory ...... 13

Figure 8. Slot openings in the chamber and bell-mouth inlets of pumps intake are marked as "A”, "B”, “C”, and "D” in the physical model (Shore et al., 2018) ................................................. 15

Figure 9. The process of finding the required area for slot A and slot B to achieve the same water

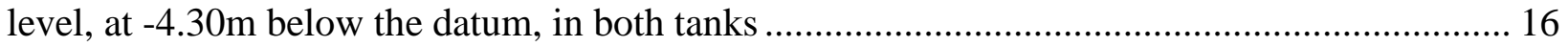

Figure 10. 3D printed tapered bell designed by WSP ..................................................... 17

Figure 11. Tapered bell design installed on line A ......................................................... 17

Figure 12. the process of analyzing the tapered bell inlet of pump intake .............................. 18

Figure 13. Water levels at each tank when the slot A opening was covered by 35\% for the pumps

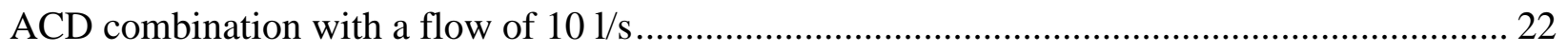

Figure 14. Inlet pipe for the pumps ACD combination with a flow of $10 \mathrm{l} / \mathrm{s}$ for each pump while

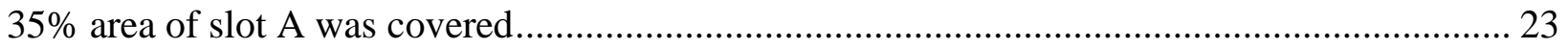

Figure 15. The 35\% area of slot A was covered by foam sheet and bricks ............................. 23

Figure 16. Depths of water fluctuations above the opening slots for the pumps ACD combination with a flow $10 \mathrm{l} / \mathrm{s}$ for each pump at a water level $-4.30 \mathrm{~m}$ under different conditions ................ 25 
Figure 17. Water level in the both tanks with pumps ABD combination with a flow of $10 \mathrm{l} / \mathrm{s}$ for each pump by blocking 35\% area of Opening A and 45\% area of Opening B............................. 28

Figure 18. Inlet pipe flow conditions for the pump ABD combination with a flow $10 \mathrm{l} / \mathrm{s}$ for each pump by blocking 35\% of Opening A and 45\% of Opening B ................................................. 29

Figure 19. Opening slots for the pump ABD combination with a flow of $10 \mathrm{l} / \mathrm{s}$ for each pump by blocking 35\% of Opening A and 45\% of Opening B .................................................................. 30

Figure 20. Depth of water fluctuations above the opening slots for the pump ABD combination with a flow $10 \mathrm{l} / \mathrm{s}$ for each pump at water level $-4.30 \mathrm{~m}$ in different conditions ............................ 31

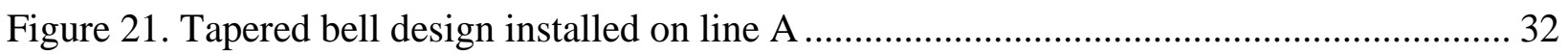

Figure 22. Dye injection at lateral and front sides of the tapered bell under low flow condition 32 Figure 23. Dye injection at the back side of the tapered bell inlet showing water rotation under low

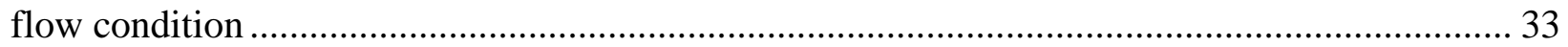

Figure 24. Dye injection at lateral and front sides of the tapered bell under cleaning cycle scenario 33

Figure 25. Dye injection at the back side of the tapered bell inlet showing water rotation under cleaning cycle scenario 33 


\section{Chapter 1.}

\section{Introduction}

\subsection{Background}

Large scale hydraulic pumping stations with one or more pumps have been broadly used by municipal wastewater services to move sewage to wastewater treatment plants. The wet well chamber of a sewage pump station consists of an approaching channel carrying wastewater from upstream sewers to the bell-shaped intake entrance of the suction pump. The approach channel can have devices such as floor and side wall splitters, flow drivers, and vans to convey the wastewater in a uniform flow condition. Generally, the overall pump performance is significantly affected by the hydraulics of flow going to a pump (Tokyay \& Constantinescu, 2006).

\subsection{Hydraulic Issues in Wastewater Pump Intake}

When flow swirls around the suction bell of the sewage pump intake, free-surface and sub-surface vortices may be formed, resulting in poor pump operation. The perfect flow condition entering the pump intake should be uniform, steady, and without direct entrainment of air by free-surface vortices. It is almost impossible to achieve a completely perfect flow condition without causing any vortices. In order to achieve a satisfactory flow condition to a sewage pump, a proper design of intake geometric factors including intake channel length $L$, pump bay shape, distance from backwall to intake pump center $X$, intake submergence (pipe depth) $S$, floor clearance $C$, sidewall clearance $L 1$ and $L 2$, pump column diameter $d$, and pump bell diameter $D m$ should be developed (Li, Lai, Weber, Silva, \& Patel, 2004). Figure 1 depicts the design features of pump intakes. Physical and numerical models are typically used to analyze the flow condition entering the suction bell and travelling through the pump column of the pump intake and determine the best design which alleviates the associated hydraulic problems. (Rodriguez, 2003). For instance, Acoustic Doppler velocimeter, Laser Doppler velocimeter, and particle image velocimetry (PIV) 
techniques are commonly used in physical models to get quantitative descriptions of the mean inflow and any vortices in the vicinity of the inlet of the pump intake while three dimensional (3D) computational fluid dynamics (CFD) models are used to simulate the flows inside the pump column.

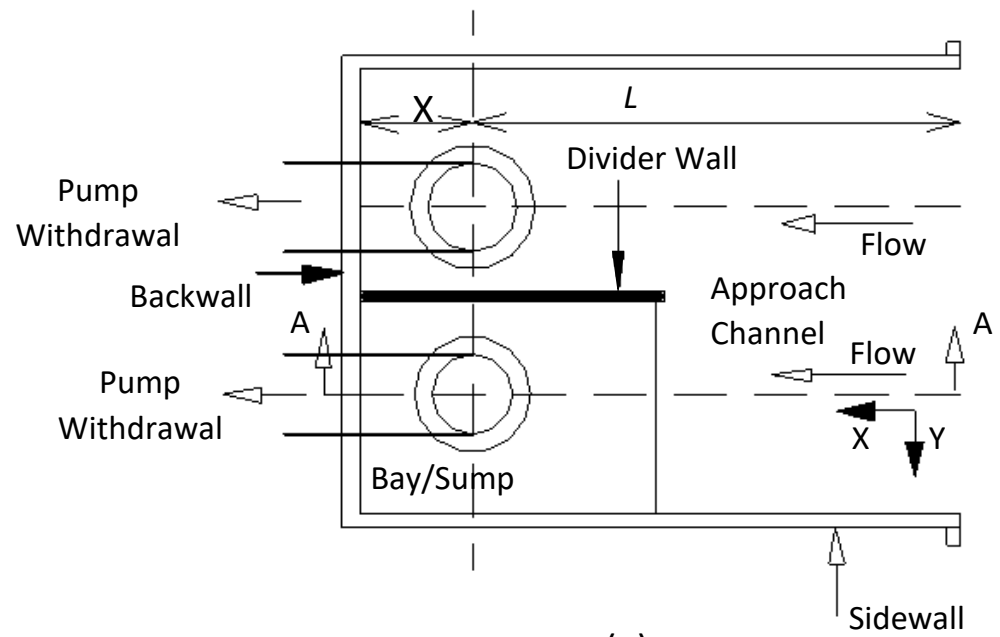

(a)

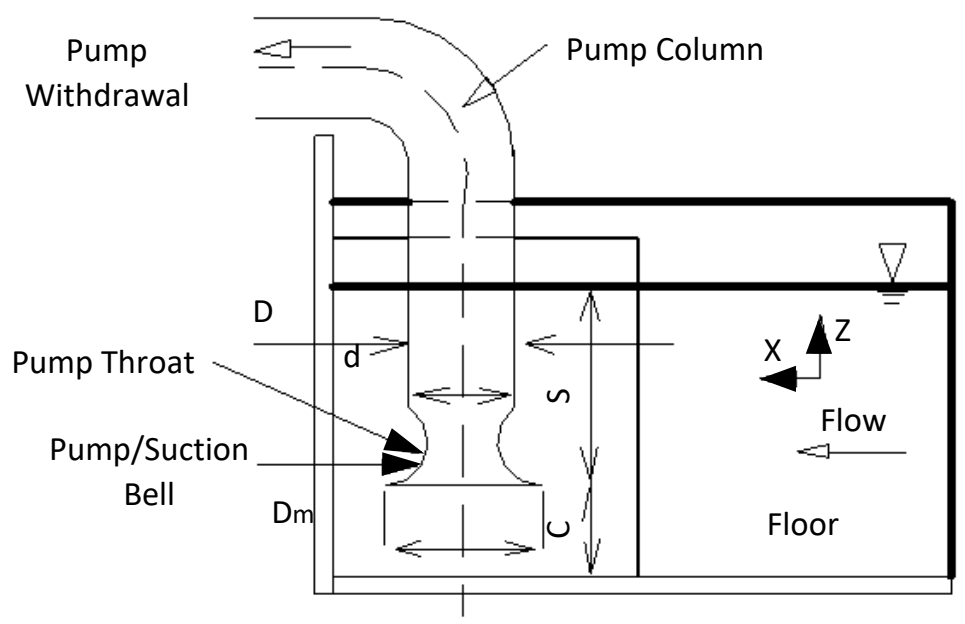

(b)

Figure 1. Typical water pump intake: (a) plan view; (b) Section A-A (adopted from Li et al., 2004) 


\subsection{Research Motivation}

In cooperation with WSP Canada Ltd., a scale/physical modeling study of the First Narrows Sewage Pumping Station was conducted by the Ryerson research team at Ryerson University's Centre of Urban Innovation laboratory. Based on the ANSI/Hydraulic Institute (HI) standard 9.8 for Pump Intake Design (2018), the physical model testing focused on flow pattern of the approach

channel and vortex formation at the bell shape entrance of the intake. This physical model study helps to ensure that the final flow condition of the approach channel be uniform and minimal formation of vortices at the bell mouth entrance of the intake. Based on the witness testing observation of any possible vortex formation, this physical model study has established the appropriate opening for the flow to enter the wet well chamber and the practical inlet shape (e.g. a tapered shape versus a bell one).

\subsection{Research Objective}

The objectives of this research are to determine:

1. The optimum entrance slot opening which distributes a uniform flow through the approach channel.

2. The tapered bell design of the intake which reduces vortex formation at the suction bell.

In order to minimize scale effects, the physical model was constructed using an effective scale of 1:4.5. The physical model test flow ranged from 10 to $16 \mathrm{~L} / \mathrm{s}$, corresponding to the minimum and the cleaning scenario flows. Ultrasonic flow meter was used to control the flow through the model. In addition, dye injections were applied to show the flow patterns at all locations where vortex might form and two (2) video cameras were used to record the tests. 


\section{Chapter 2.}

\section{Literature Review}

The studies listed below describe the collection of experimental data and the calibration/validation of numerical models which were then used to simulate the three-dimensional flow pattern and potential vortex formation at pump intake bays.

Kim, Bang, and Lee (2015) conducted a physical model experiment (scale 1:10) to check flow conditions around a pump intake. A Computational fluid dynamics (CFD) model was used for sump pump flow simulations. In this research the uniformity of the flow in the intake pump was investigated to detect potential vortex formation. Moreover, an anti-vortex device (AVD) was used to examine the its efficiency to suppress the vortex formation at this single water-intake-pump. The CFD model results and the experimental data with and without AVDs are in a generally good correspond in both results.

J W Choi, Y D Choi, Kim, and Lee (2010) investigated the cause of vortex occurrence at water intake pumps. A multi-intake pump sump and a single water-pump intake were fabricated for the experiment. The results showed that the flow uniformity differs in different inlet of pump intakes. Therefore, the flow pattern in the approach channel should be considered in detail because the nonuniform flow could cause vortex formation near the bell-mouth intake. Additionally, the effectiveness of anti-vortex device (AVD) was examined and the AVD was found to successfully suppress strong submerged vortices.

Li, Lai, Weber, Silva, and Patel (2004) used the experimental results of a previous CFD study to validate their newly developed numerical model of a water intake pump. Generally, the numerical results of the new model were in good agreement with experimental outcomes in terms of size and strength of vortices. The improvement in the new numerical model over the previous one was associated to numerical solution procedure.

Rajendran, Constantinescu, and Patel (1999) performed a laboratory experiment to calibrate/validate a numerical model for the simulation of the three-dimensional turbulent flow in a water-intake pump bay. The numerical model focused on the estimation of the vortex's 
properties. The predicted properties of vortices including number, location, and general structure were in a good agreement with those measured in the experiment. However, the measured vortices were either smaller or stronger than the predicted ones.

Tokyay and Constantinescu (2006) developed a numerical model to estimate water-pump-intake flow pattern and potential vortex formation. Large-eddy simulation (LES) was applied to predict the flow pattern in this study. The collected particle image velocimetry data at the laboratory were used to validate the results of the LES model. For better understanding of the LES performance, the results from steady simulations which employed the shear stress transport (SST) were described and compared with those of the LES. Although the model with SST predicted the mean velocity distribution, the model with LES could estimate more precisely the mean flow and turbulence statistics.

Chuang and Hsiao (2011) investigated the hydrodynamics of a water-intake pump using Truchas with a large-eddy simulation (LES). The flow patterns and streamwise velocity results from the numerical model were compared with the experimental results of a previous research done by Ansar and Nakato (2001). The comparison showed a good agreement between numerical and experimental data. Moreover, the results indicated that the flow pattern could be affected by viscosity and the cross flow could help to better capture the streamwise velocity. 


\section{Chapter 3.}

\section{The Scale/Physical Scale Model}

Hydraulic modeling of the First Narrows Sewage Pumping Station's wet well requires a detailed analysis of the three-dimensional flows at the approach channel and the pump intake. Poor design of the wet well can lead to air entrainment and water spin in vortices near the intake pump inlet. In order to achieve desirable flow characteristics throughout the wet well both physical and numerical models should be used (Product \& Two, 1966).

\subsection{Similitude and Scale Selection}

The design of the physical model of the First Narrows Sewage Pumping Station was completed by following the ANSI/Hydraulic Institute (HI) standard 9.8 (hereafter HI standard) which is the most update standard for pump suction and wet well design (Shore, Treatment, \& Conveyance, 2018). The HI standard recommends that the physical modeling of wet wells should be scaled using the Froude similarity. The Froude Number $(F)$ which is the ratio of flow inertia to the external field (in many applications simply due to gravitational forces) is defined for pump intake as:

$$
F=\frac{u}{\sqrt{g L}}
$$

$\mathrm{F}=$ Froude Number

$\mathrm{u}=$ flow velocity

$\mathrm{g}=$ acceleration of gravity

$\mathrm{L}=$ characteristic length (usually bell diameter or submergence)

The HI standard also defines constraints on the Reynold and Weber Number at the suction bell to minimize the effect of viscous and surface tension: 


$$
R=\frac{u D}{v} ; R \geq 3 \times 10^{4}
$$

$\mathrm{R}=$ Reynolds Number

$\mathrm{D}=$ diameter (of the bell entrance)

$v=$ kinematic viscosity of the fluid

$$
W e=\frac{u^{2} D}{\frac{\sigma}{\rho}} ; E>120 \text { (Weber Number) }
$$

We $=$ Weber Number

$\sigma=$ surface tension of liquid

$\rho=$ liquid density

The Reynold number at the pump suction is suggested to be $\geq 1 \times 10^{5}$.

To determine the Froude number of the physical model, the ratio of Froude Number of the model and the prototype is given below.

$$
F r=\frac{F m}{F p}=1
$$

Where $\mathrm{m}$ and $\mathrm{p}$ represent the model and prototype respectively. Also, $\mathrm{r}$ defines the ratio between model and prototype parameters to assure dynamic and surface tension scale are measured considerably.

There are some constraints in the size of the physical model to obtain accurate measurements including the minimum 300 mm (12 in) of bay width, minimum 150 mm (6 in) of liquid depth, and minimum 80 mm (3 in) of pump throat or suction diameter (Shore et al., 2018).

By considering all the mentioned similitude consideration and adding a safety factor of 2 in the calculations of Reynolds number and Weber number for the bell inlet, a scale of 1:4.5 was obtained to be efficient for the physical model and meet all the requirements in HI standard (Shore et al., 
2018). Detailed calculation for finding the most efficient scale including calculated flows, pressure and velocities within the prototype and scale modeling are described in Appendix A.

\subsection{Physical Model Study Purpose}

The physical model of the pump intake and the suction lines should adhere to HI standards criteria in order to achieve a desirable flow condition for testing. The CFD model developed by WSP Canada Ltd. is appropriate for simulating boundary conditions, but the velocity, swirl, surface depression, and other complex flow phenomena should be quantified using the physical model properly. The physical model was designed and constructed as shown in Figure 2 to evaluate the hydraulic conditions, leading to design modification as needed. In this study, hydraulic conditions including air entrainment, free and subsurface vortex formation, swirl, and velocity nonuniformities that can affect the pump performance and efficiency were evaluated. Hence, using the scale model to simulate any aforementioned hydraulic issues, design modifications can be done to provide satisfactory wet well performance in accordance to HI standards for pump intake design (Shore et al., 2018).

The simulation of sediments was not necessary in the physical model study because the CFD model results were sufficient. Additionally, scaling of sediments in physical models is complex. Dye injection was used to determine the areas of water recirculation and low velocity (Shore et al., 2018).

\subsection{The Scale Model}

As shown in Figure 2, the model was fed by the laboratory water supply system. Intake pump pushed water to the head tank which then flowed to the inlet pipe of the model. An ultrasonic flow meter was used to control the flow through the model. The required water level was balanced by controlling the inflow and outflow through the model (two tanks). 


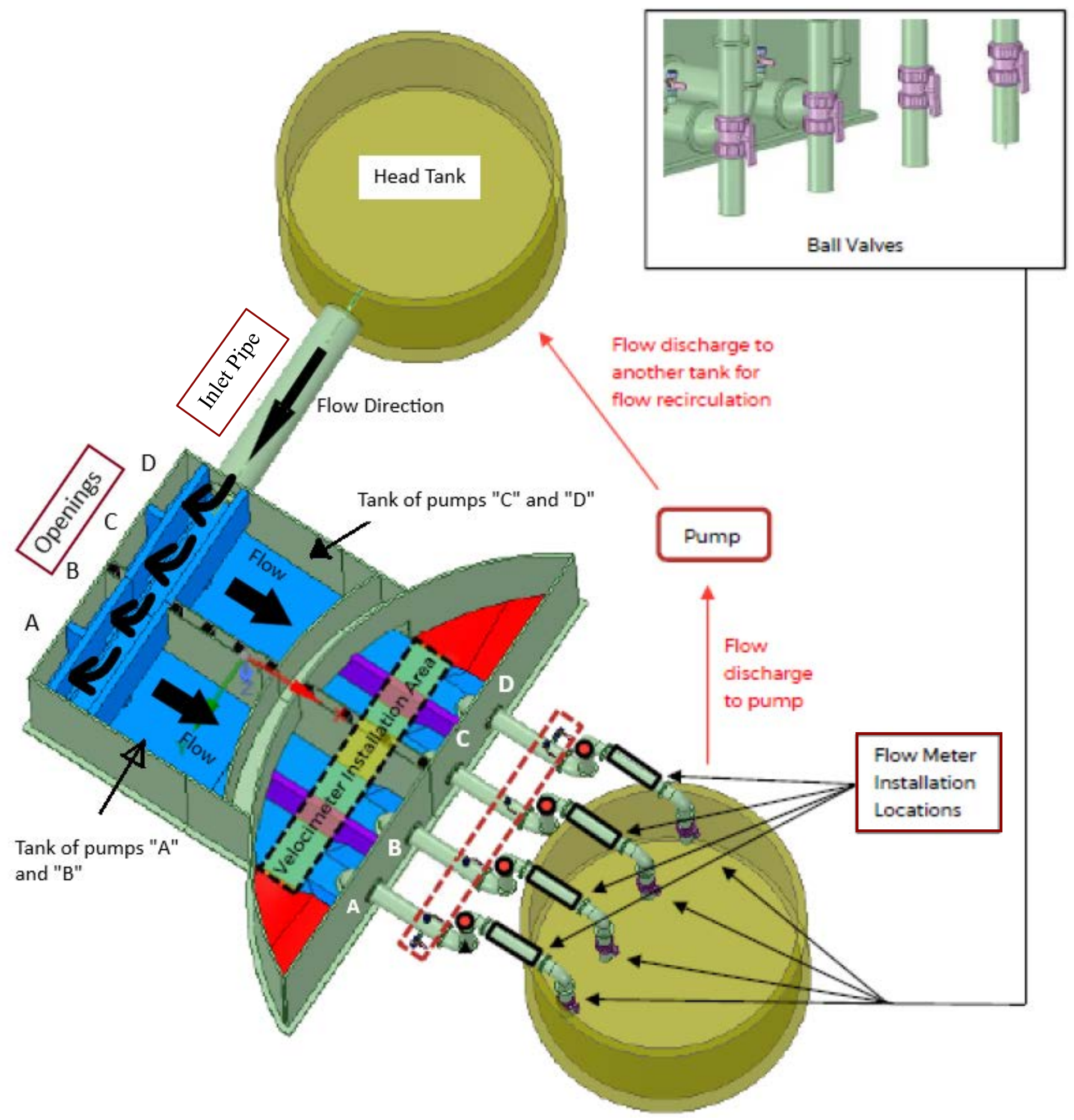

Figure 2. A tridimensional (3D) view of the physical model of the First Narrows Sewage Pump Station wet well and location of the instruments (Shore et al., 2018) 
Figure 3 shows the side view of the scale modeling including the key dimensions. The scale model has an inlet pipe diameter of $270 \mathrm{~mm}$, a suction pipe diameter of $134 \mathrm{~mm}$, and a pump inlet of 89 mm (Shore et al., 2018). As shown in Figure 4, water enters the chamber from the inlet pipe. Then it goes through different openings named A, B, C, and D and fills two tanks.

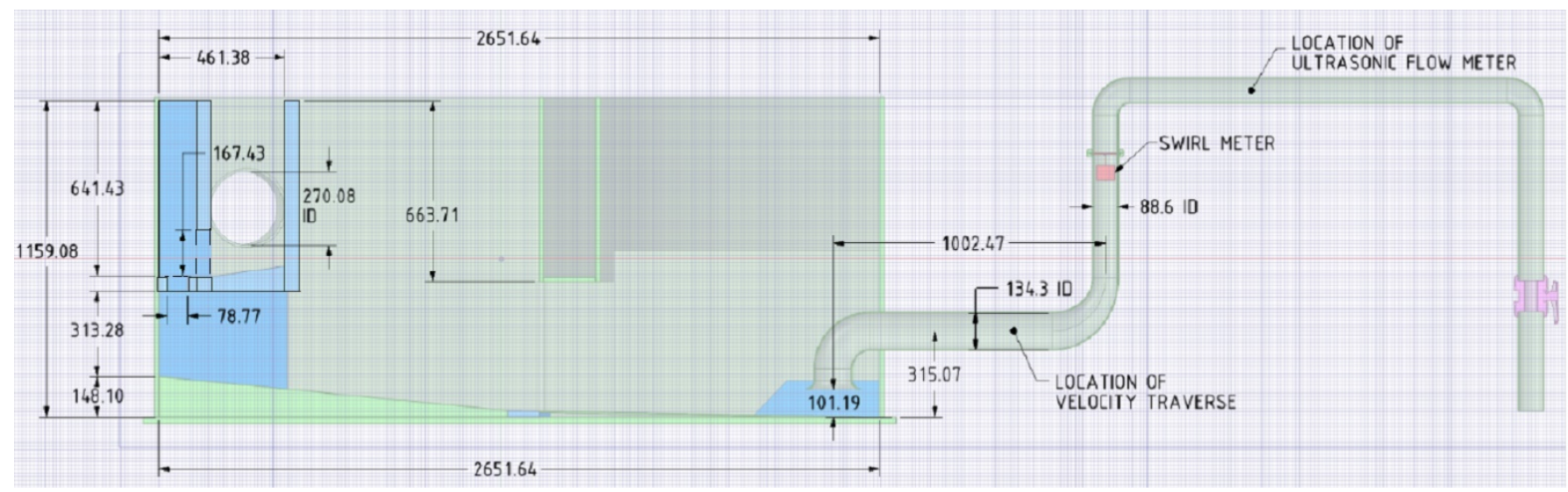

Figure 3. Side view of the physical model and dimensions (Shore et al., 2018)

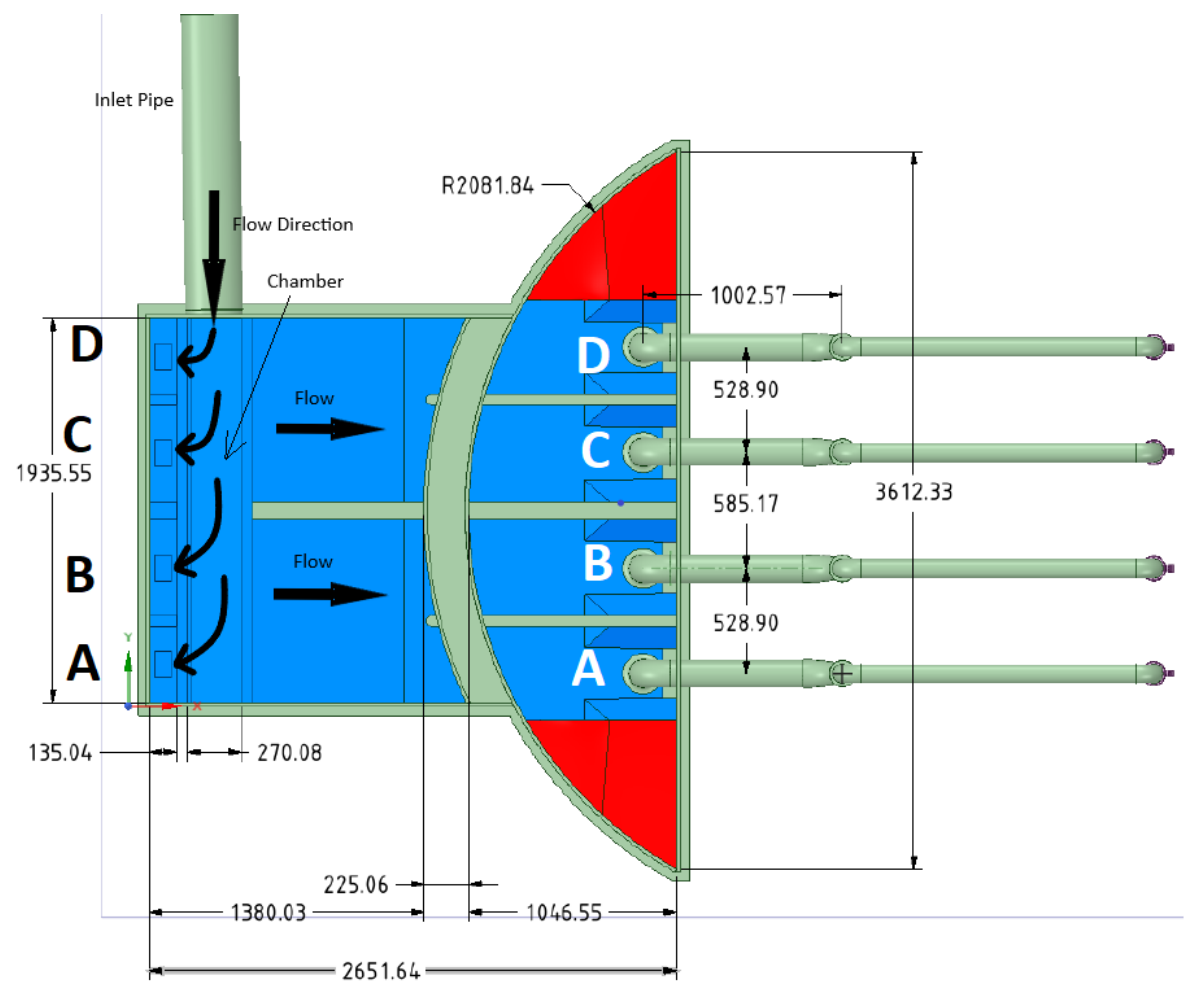

Figure 4. Plan view of the physical model and dimensions (Shore et al., 2018) 
Part of the scale model was constructed using clear plastic or smooth fiber glass materials in order to allow observation of flow condition and potential vortex formation at critical areas. These transparent components are shown with green color in Figure 5. Other parts colored in orange in Figure 5 were constructed by opaque materials which provided a soft background to see the dye movement. The bell-mouth inlet of the intake pump and pipe bends were manufactured by 3D printing to achieve the desirable shape (Shore et al., 2018). As indicated in Figure 5, the model has two separate tanks, one on the left side of middle orange wall and the other one on the right side of the middle orange wall which are connected through the chamber.

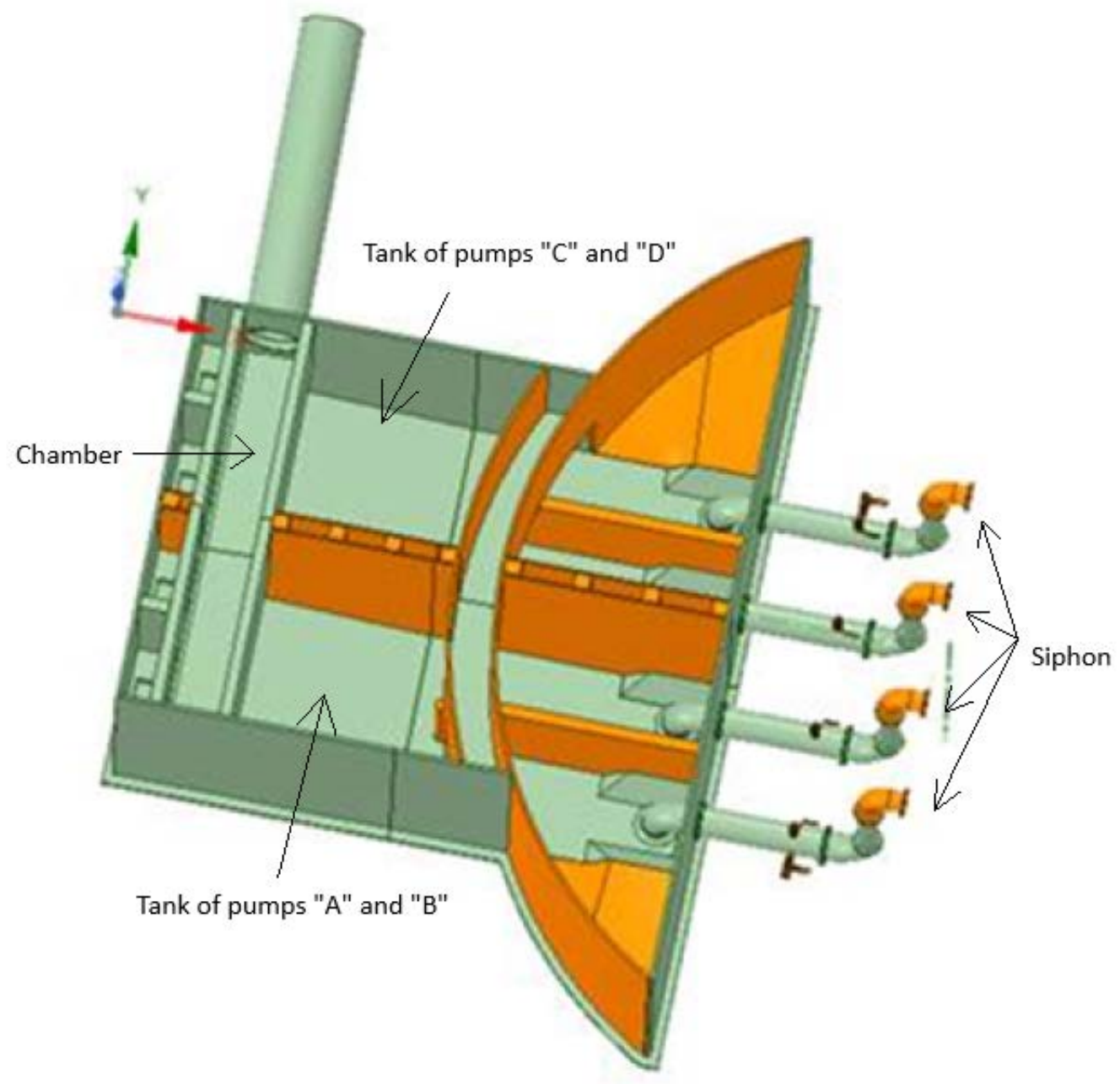

Figure 5. "Translucent and opaque components for flow visualization (Green is translucent and orange is opaque)" (Shore et al., 2018) 


\subsection{Instrumentation and Measuring Techniques}

In order to balance the water level in the model and achieve the required flows, a siphon is connected to each suction pipe to transfer water to a pump and then discharge it to head tank where the inlet pipe is located. This process helps water to circulate in the model.

The measuring instruments and techniques as required by the HI standards (Shore et al., 2018):

a. A flow meter, U1000MKII-FM - Fixed Ultrasonic Flow Meter supplied by Hoskin, was used at the siphon tubes to measure the outflow of each pump.

b. The water level in the model was determined by a measurement tape which was stuck on the translucent parts of the model.

c. The dye injection was used to observe the potential vortex formation near the bell-mouth and flow patterns at all locations. A camera was used to record the dye movement.

\subsection{Scale Model Construction}

The physical model of the First Narrows Sewage Pumping Station was constructed by the WSP team at the Ryerson Centre of Urban Innovation's laboratory. Figures 6 and 7 show the constructed model based on all the aforementioned criteria. 


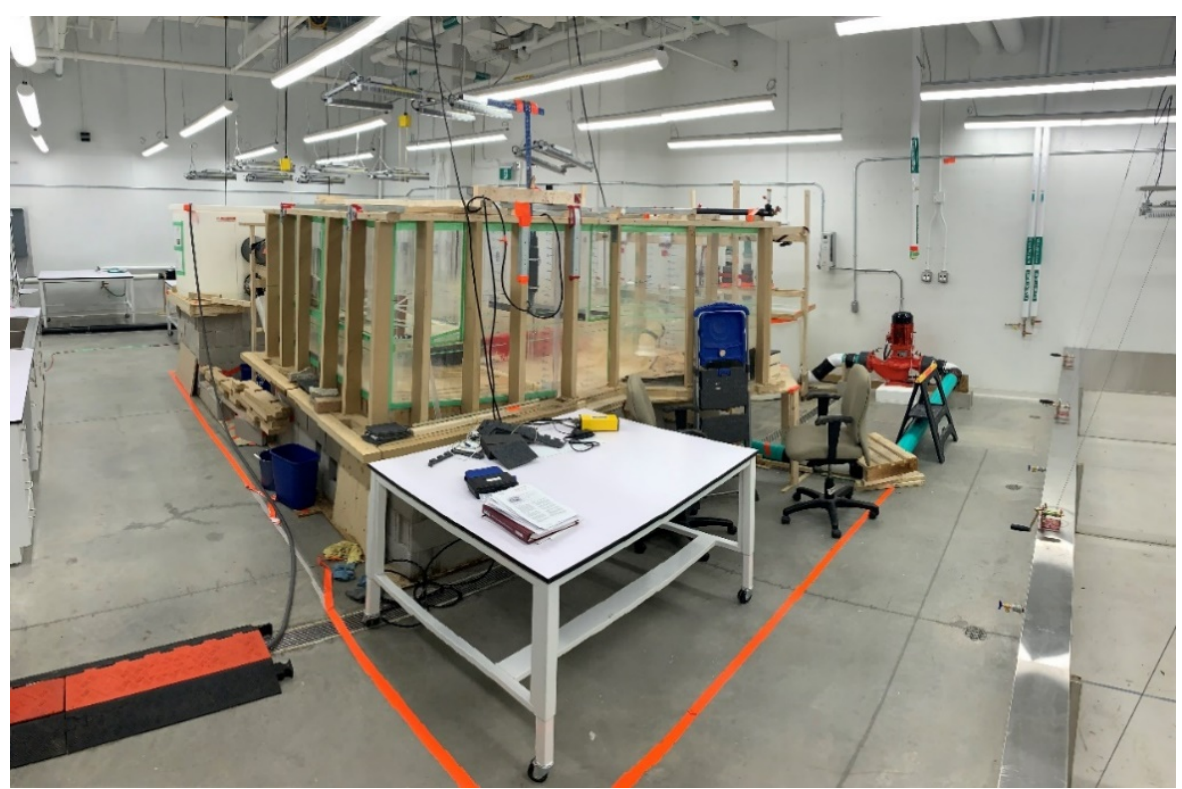

Figure 6. An upstream view of the constructed physical model at the Ryerson laboratory

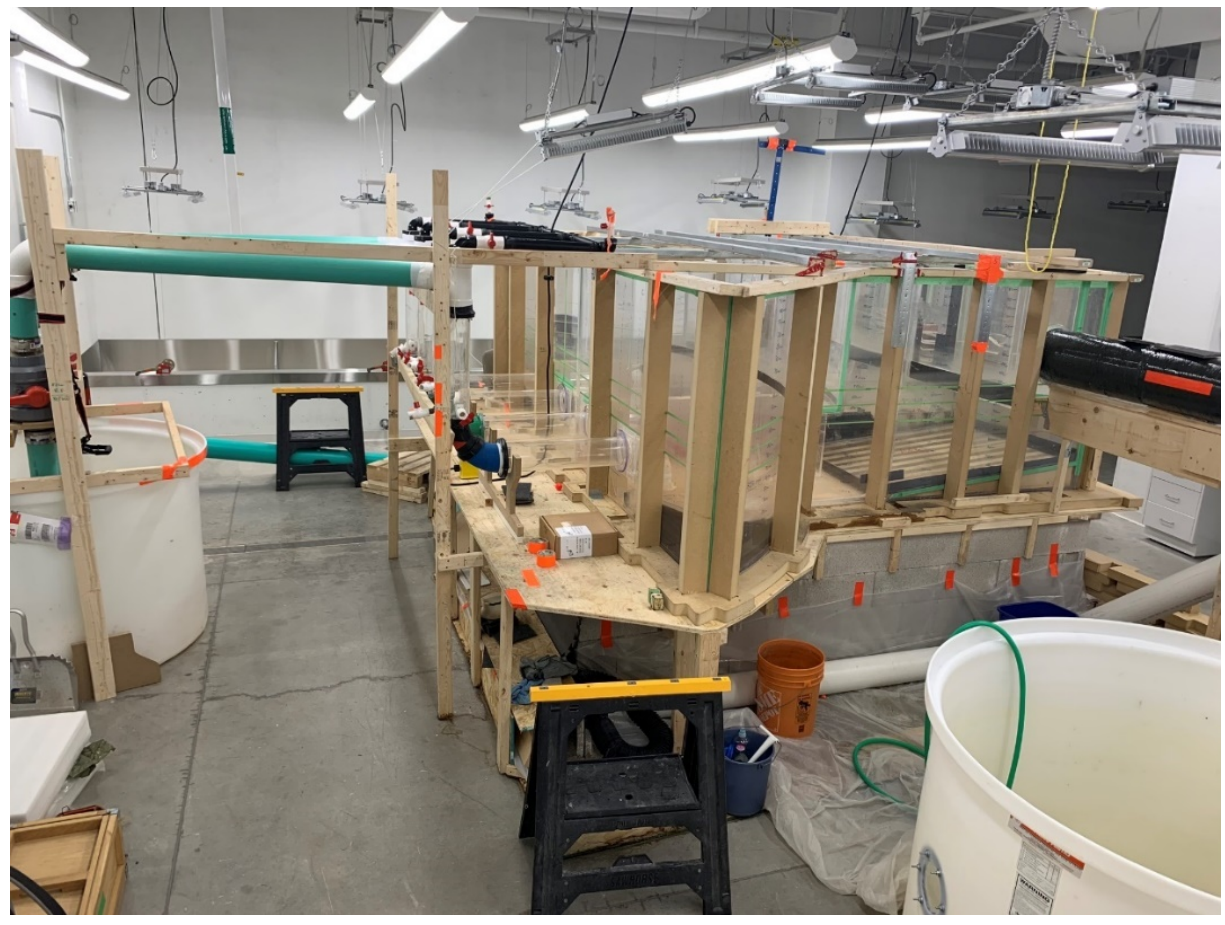

Figure 7. A downstream view of the constructed physical model at the Ryerson laboratory 


\section{Chapter 4.}

\section{Experimental Methodology}

WSP performed the following six scenarios on the wet well scale model for the 2021 flow condition (Shore et al., 2018).

Scenario 1: peak wet weather flow (3 pumps ON)

Scenario 2: twice the average dry weather flow (2 pumps ON)

Scenario 3: average flow (2 pumps ON) at energy level (normal) and under level-control

Scenario 4: minimum flow: (1 pump ON)

Scenario 5: cleaning cycle (1 pump ON)

Scenario 6: all pumps running at full speed (4 pumps ON)

The experiment of this study is described in Section 4.1.

\subsection{General Description of the Experiment}

As described in Section 1.4, the objective of this research is determining (1) the optimum entrance slot opening size which distributes a uniform flow through the approach channel; and (2) the tapered bell design of the intake which reduces vortex formation at the suction bell.

\subsection{Procedure of Testing to Achieve Even Water Distribution in the Chamber}

The slot openings and the bell-mouths inlets of the pump intake are marked in Figure 8. The physical model was run under firm capacity with two different combinations of pumps: ABD and ACD. The water levels above the opening slots in the chamber and the water at both tanks at the wet well were recorded during the experiments. The area of the opening slots was decreased by 
blocking them partially and the water levels in the chamber was recorded including the head difference at both tanks.

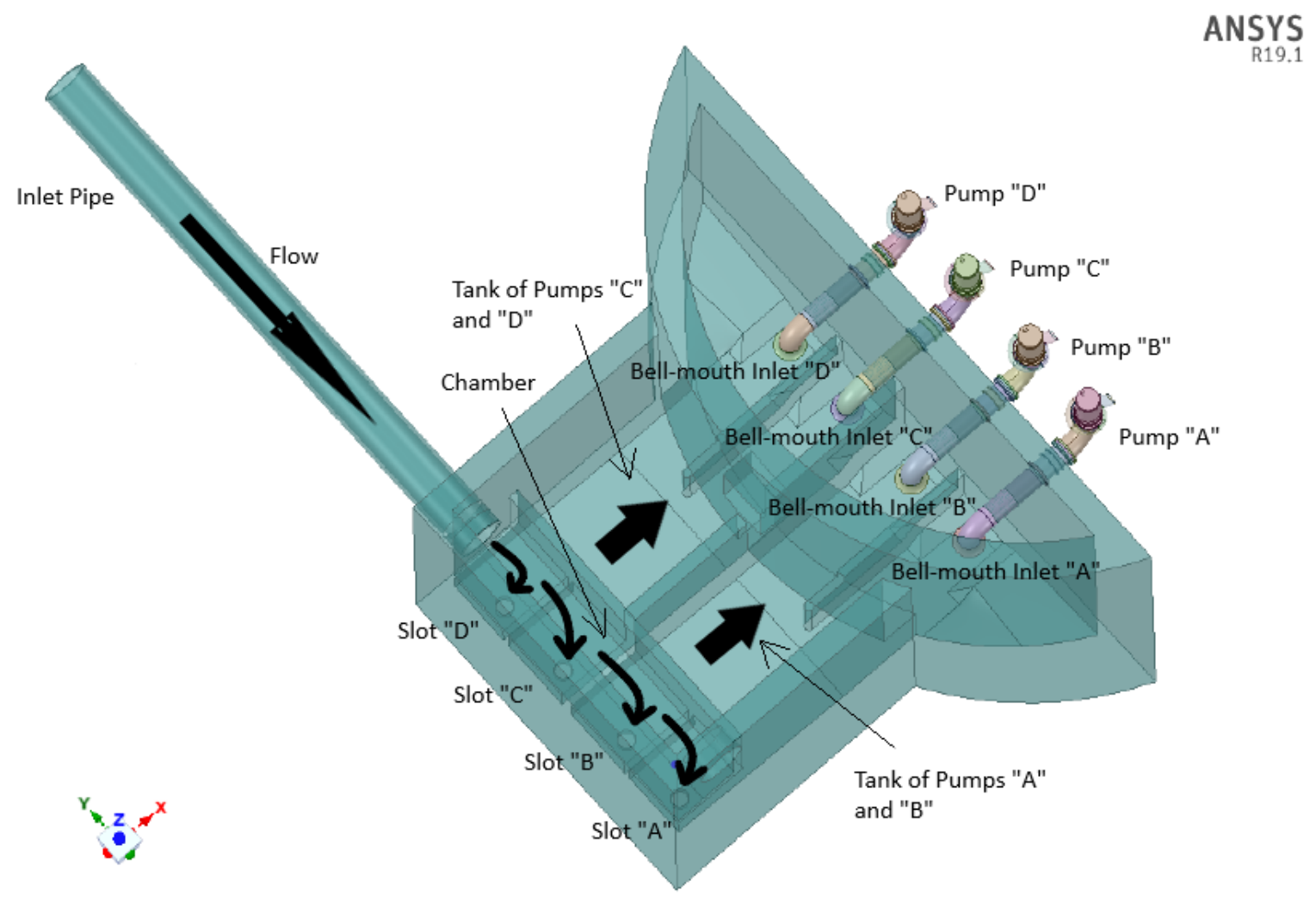

Figure 8. Slot openings in the chamber and bell-mouth inlets of pumps intake are marked as "A", "B", "C", and "D" in the physical model (Shore et al., 2018)

The water flow enters the chamber and goes through the opening slots to fill the tanks. The chamber is a closed box and water flow would stop after passing opening slot A. Hence the water depth above the opening slots $\mathrm{A}$ and $\mathrm{B}$ increase and more flow goes to tank of pumps $\mathrm{A}$ and $\mathrm{B}$ resulting head difference between the two tanks. During the testing pump combination ACD with a flow of $10 \mathrm{l} / \mathrm{s}$ and water level $-4.30 \mathrm{~m}$ below the datum, slot opening $\mathrm{A}$ is covered partially to achieve the same water level in both tanks. After finding the proper size for slot opening $A$, the model was then run for ABD combination. While the slot size of A was reduced as a result of last step, the slot size of B is covered partially to obtain the same water level in both tanks. Figure 9 
shows the process of finding the required area for slot A and slot B to achieve the same water level, at $-4.30 \mathrm{~m}$ below datum, in the both tanks.

Run the physical model with pump combination ACD

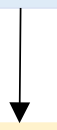

Set $10 \mathrm{l} / \mathrm{s}$ flow for each pump and water level at $-4.30 \mathrm{~m}$

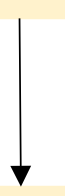

Cover the slot A partially to achieve the same water level in both tanks

Find the required area for slot A
Run the physical model with pump combination

ABD

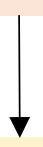

Set $10 \mathrm{l} / \mathrm{s}$ flow for each pump and water level at -

$4.30 \mathrm{~m}$

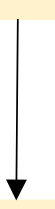

While the slot A size is reduced, cover the slot B partially to achieve the same water level in both tanks

\section{Find the required area for slot}

B

Figure 9. The process of finding the required area for slot A and slot B to achieve the same water level, at $-4.30 \mathrm{~m}$ below the datum, in both tanks 


\subsection{Procedure of Testing to Analyze the Tapered Bell Design}

The tapered suction bell installed on line A, is the most critical area for vortex formation, because it has the space for surface water rotation (i.e. The red area in Fig. 4 at Pump A). Figures 10 and 11 depict the tapered bell design and its fabrication on line A using Gorilla heavy duty construction adhesive and rubber gaskets. Then the physical model was run for the low flow condition (Pump A working with a flow of $10 \mathrm{l} / \mathrm{s}$ at water level $-5.10 \mathrm{~m}$ ) and cleaning cycle scenario (Pump A working with a flow of $16 \mathrm{l} / \mathrm{s}$ at water level $-4.9 \mathrm{~m}$ ). Dye injection was applied around the tapered bell inlet for observation of flow pattern and potential vortex formation.

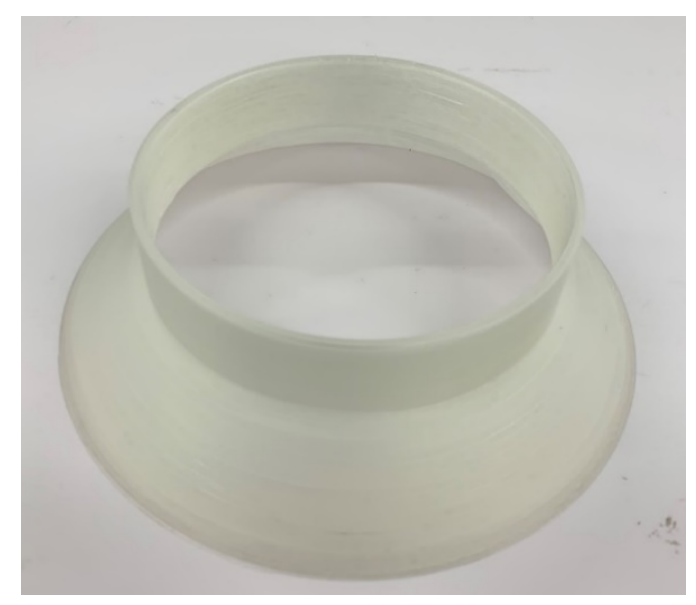

Figure 10. 3D printed tapered bell designed by WSP

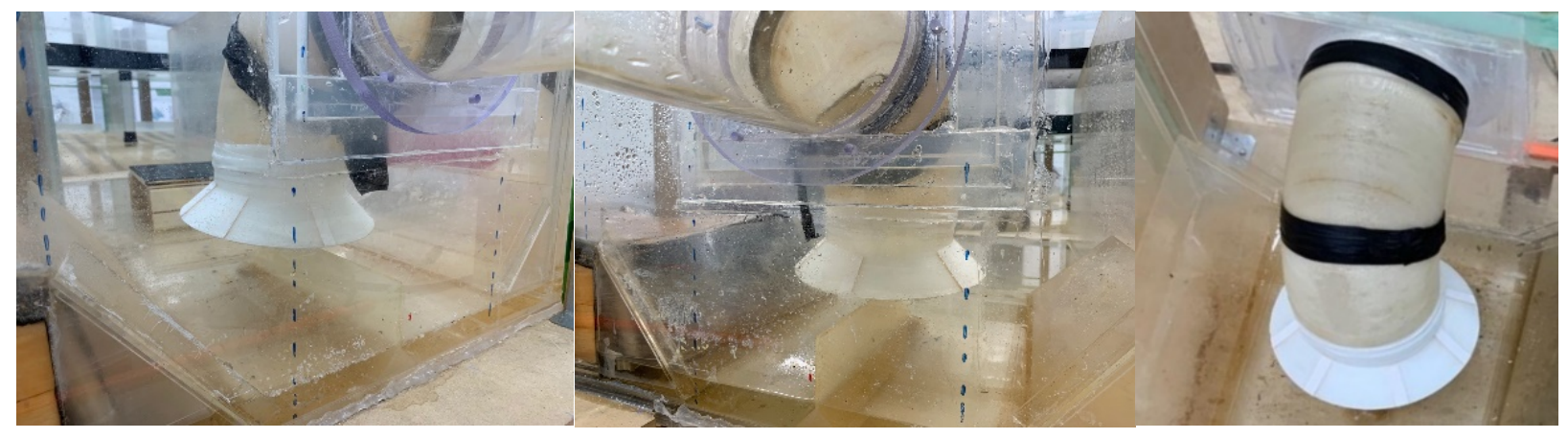

Figure 11. Tapered bell design installed on line A 
Figure 12 shows the process of analyzing the tapered bell inlet of pump intake.

Run the physical model under pump A working

Set a flow of $10 \mathrm{l} / \mathrm{s}$ (low flow condition) for pump "A" at water level $-5.10 \mathrm{~m}$ below the datum

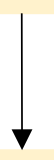

Apply dye injection around tapered bell inlet

Observe any vortex formation around tapered bell inlet and record video of the flow pattern
Run the physical model under pump A working

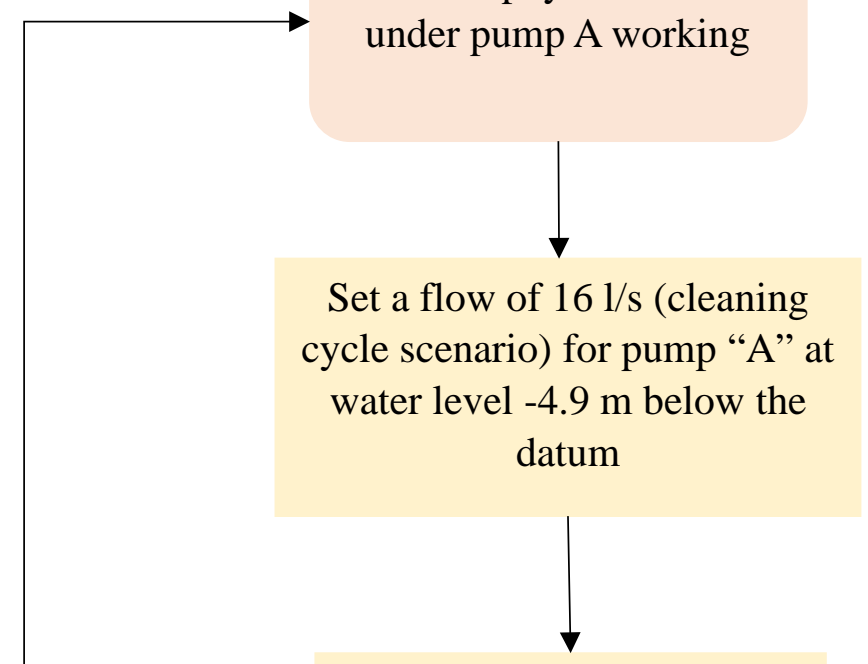

Apply dye injection around tapered bell inlet

Observe any vortex formation around tapered bell inlet and record video of the flow pattern

Figure 12. the process of analyzing the tapered bell inlet of pump intake 


\subsection{Experimental Data Analysis}

The experiments were recorded by camera in picture format and videos. Measurements were marked on the clear plastic parts of the model to ensure the water level achieved the desirable height. The slot openings A and B were covered partially by foam sheets and were fixed with the bricks. Dye injection was used to determine the potential vortex formation near the tapered bell design. Vortices was recorded in video and watched frame by frame to see the water movement. 


\section{Chapter 5.}

\section{Experimental Results and Discussion}

\subsection{Pump Combination ACD}

The test showed that at 35\% blockage of the slot opening A, the water levels $(-4.30 \mathrm{~m}$ below the datum) were the same at both tanks. Using the measured flows at openings (A, C, and D), the discharge coefficient of each opening slot was determined.

\subsubsection{Procedure of Finding the Required Size for Opening Slot A}

Experiments were run with the existing flow condition at $10 \mathrm{l} / \mathrm{s}$ for each line (at a balanced water level $-4.30 \mathrm{~m}$ ). Since there was a head difference of $113 \mathrm{~mm}$ between the two tanks, the proper area for slot A to achieve the same water level in two tanks was determined. The water level in the chamber above each slot was also measured.

The slot size of opening A was blocked by $40 \%$ and the water level in the chamber above each slot (A, C, and D) was measured. The experiment showed that the blockage was more than the required area and there was still a head difference between the two tanks. When the slot A was blocked by $35 \%$, the water levels at both tanks were the same at $-4.30 \mathrm{~m}$. Tables 1 to 3 show opening measurements when the ACD pumps worked at a flow of $10 \mathrm{l} / \mathrm{s}$. 
Table 1. Experimental measurements for the pumps ACD combination with a flow of $10 \mathrm{l} / \mathrm{s}$ for at each pump

\begin{tabular}{|c|c|c|c|}
\hline $\begin{array}{c}\text { Slot } \\
\text { Opening }\end{array}$ & $\begin{array}{c}\text { Percentage of } \\
\text { Opening } \\
\text { Blocked }\end{array}$ & $\begin{array}{c}\text { Area of Opening } \\
\mathbf{( m}^{\mathbf{2}}\end{array}$ & $\begin{array}{c}\text { Depth of Water Measured from the } \\
\text { Center of Opening (m) }\end{array}$ \\
\hline A & 0 & 0.01163 & 0.208 \\
\hline C & 0 & 0.01163 & 0.174 \\
\hline D & 0 & 0.01163 & 0.10 \\
\hline \multicolumn{2}{l}{ Head water difference between two tanks: $\mathbf{1 1 3} \mathbf{~ m m}$} \\
\end{tabular}

Table 2. Experimental measurements by covering $40 \%$ of the opening A for the pumps ACD combination with flow of $10 \mathrm{l} / \mathrm{s}$ at each pump

\begin{tabular}{|c|c|c|c|}
\hline $\begin{array}{c}\text { Slot } \\
\text { Opening }\end{array}$ & $\begin{array}{c}\text { Percentage of } \\
\text { Opening } \\
\text { Blocked }\end{array}$ & $\begin{array}{c}\text { Area of Opening } \\
\mathbf{( m}^{\mathbf{2}}\end{array}$ & $\begin{array}{c}\text { Depth of Water Measured from the } \\
\text { Center of Opening (m) }\end{array}$ \\
\hline A & $40 \%$ & 0.00698 & 0.242 \\
\hline C & 0 & 0.01163 & 0.22 \\
\hline D & 0 & 0.01163 & 0.188 \\
\hline \multicolumn{2}{|l}{ Head water difference between two tanks: $\mathbf{7 0 ~} \mathbf{~ m m}$} \\
\end{tabular}

Table 3. Experimental measurements by covering $35 \%$ of the opening A for the pumps ACD combination with flow $10 \mathrm{l} / \mathrm{s}$ at each pump

\begin{tabular}{|c|c|c|c|}
\hline $\begin{array}{c}\text { Slot } \\
\text { Opening }\end{array}$ & $\begin{array}{c}\text { Percentage of } \\
\text { Opening } \\
\text { Blocked }\end{array}$ & $\begin{array}{c}\text { Area of Opening } \\
\mathbf{( m}^{\mathbf{2}}\end{array}$ & $\begin{array}{c}\text { Depth of Water Measured from the } \\
\text { Center of Opening (m) }\end{array}$ \\
\hline A & $35 \%$ & 0.00756 & 0.228 \\
\hline C & 0 & 0.01163 & 0.21 \\
\hline D & 0 & 0.01163 & 0.153 \\
\hline \multicolumn{2}{|l}{ Head water difference between two tanks: $\mathbf{0 ~} \mathbf{m m}$} \\
\end{tabular}


As shown in Table 3 and Figure 13, the head water difference between the two tanks was zero by blocking 35\% of Opening A.
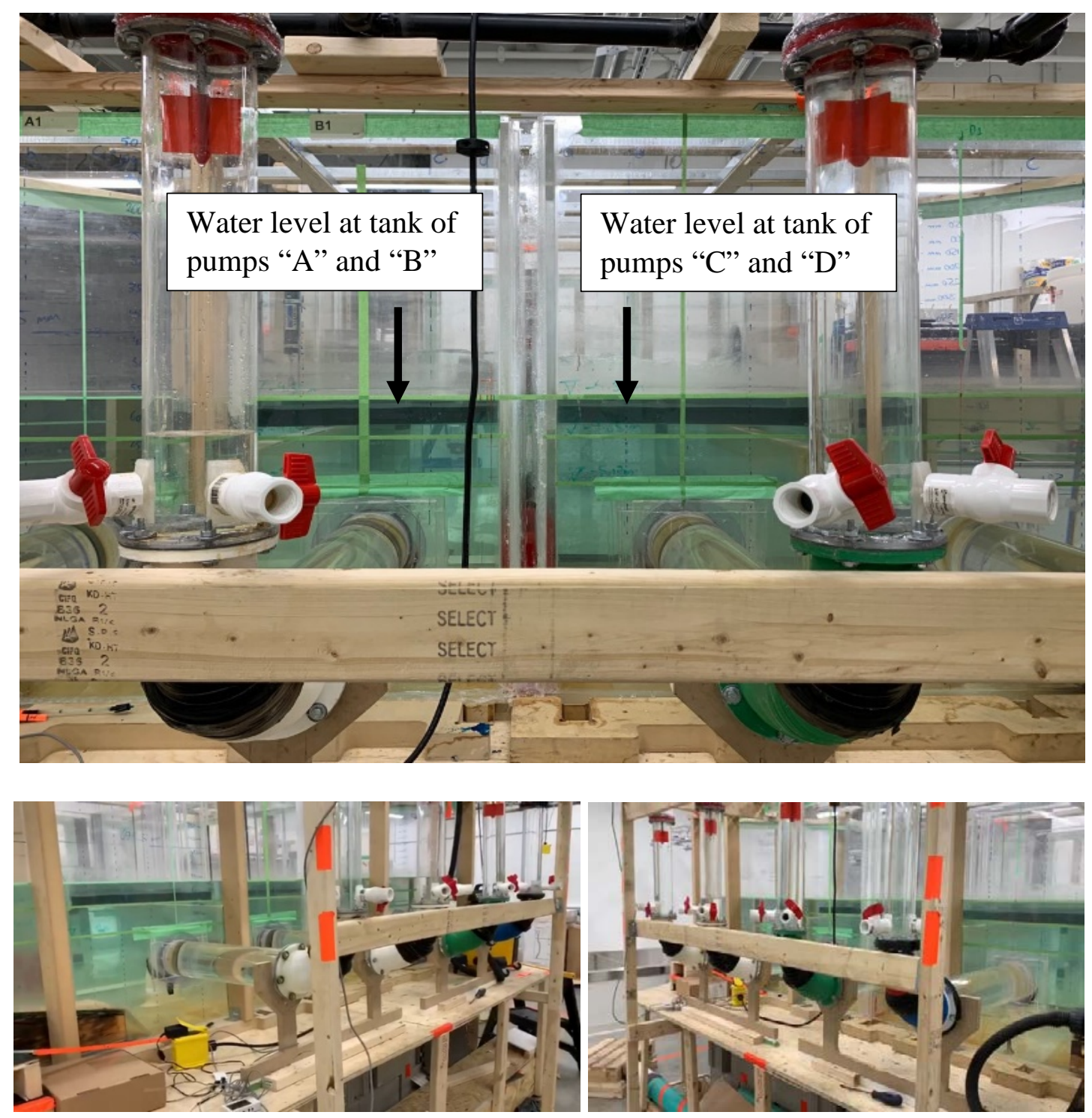

Figure 13. Water levels at each tank when the slot A opening was covered by $35 \%$ for the pumps ACD combination with a flow of $10 \mathrm{l} / \mathrm{s}$

The inlet pipe with length $1200 \mathrm{~mm}$ was extended far enough upstream to provide condition for uniform flow entering chamber (Shore et al., 2018). It can be noticed from Figure 12 that the inlet pipe is not filled which is vital for conveying future demand to the system. 


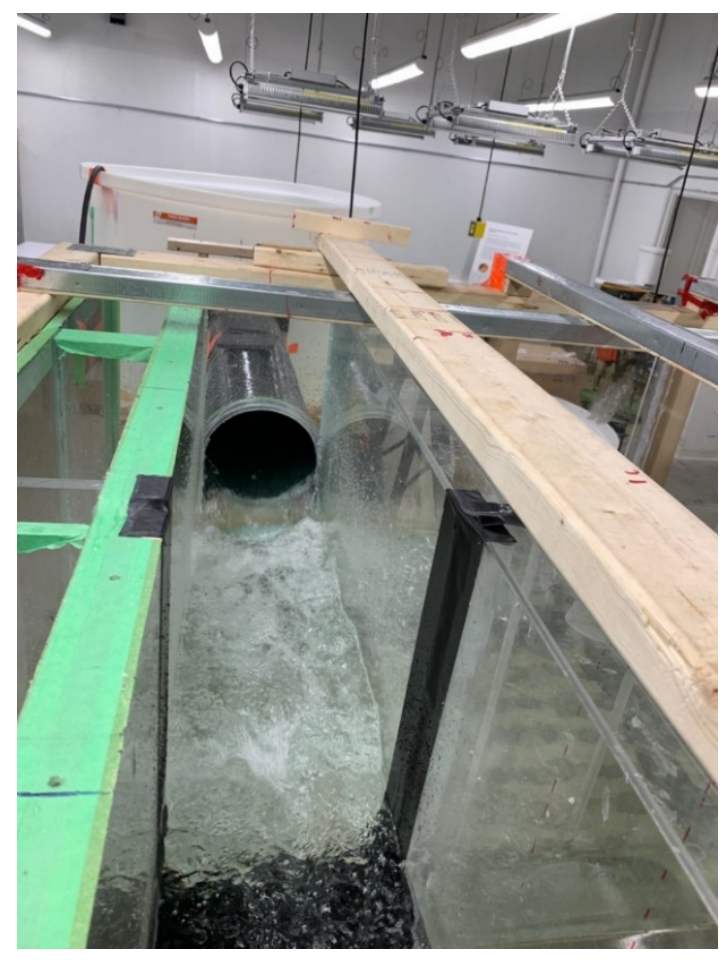

Figure 14. Inlet pipe for the pumps ACD combination with a flow of $10 \mathrm{l} / \mathrm{s}$ for each pump while $35 \%$ area of slot A was covered

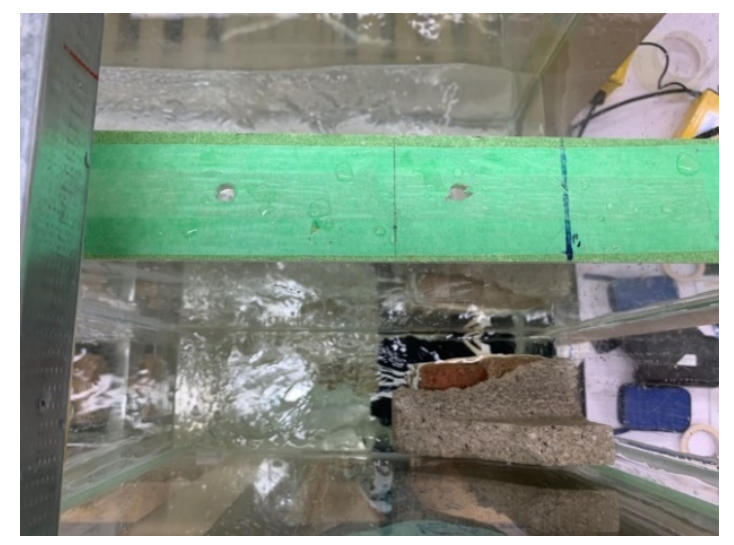

Figure 15 . The 35\% area of slot A was covered by foam sheet and bricks

The orifices flow equation given below (slot as an orifice) was applied to find the coefficient of discharge for the slots. 


$$
Q=C A \sqrt{2} g h
$$

$\mathrm{Q}=$ discharge in cubic meter per second $\left(\mathrm{m}^{3} / \mathrm{s}\right)$

$\mathrm{C}=$ coefficient of discharge (the ratio of actual discharge to the theoretical discharge)

$\mathrm{A}=$ area of opening in square meter $\left(\mathrm{m}^{2}\right)$

$\mathrm{g}=9.81 \mathrm{~m} / \mathrm{s}^{2}$

$\mathrm{h}=$ depth of water measured from the center of the opening $(\mathrm{m})$

Table 4 shows the estimated discharge coefficients of Openings A, C, and D for the pumps ACD combination at a flow of $10 \mathrm{l} / \mathrm{s}$ and 35\% coverage of Opening A which achieved the same water level in both tanks at $-4.30 \mathrm{~m}$.

Table 4. Estimation of discharge coefficient of Openings A, C, and D for the pumps ACD combination at a flow of $10 \mathrm{l} / \mathrm{s}$ and $35 \%$ covering of Opening A

\begin{tabular}{|c|c|c|c|c|}
\hline Opening & $\begin{array}{c}\text { Area of opening } \\
\left(\mathbf{m}^{\mathbf{2}}\right)\end{array}$ & $\begin{array}{c}\mathbf{g} \\
\mathbf{( m / \mathbf { s } ^ { 2 } )}\end{array}$ & $\begin{array}{c}\text { Depth of water } \\
\text { above the slot } \\
\mathbf{( m )}\end{array}$ & $\begin{array}{c}\text { Estimated Coefficient of } \\
\text { discharge }\left(\mathbf{C}=\mathbf{Q} / \mathbf{A}^{*} \sqrt{\mathbf{2} g h}\right)\end{array}$ \\
\hline $\mathbf{A}$ & 0.00756 & 9.81 & 0.228 & 0.63 \\
\hline $\mathbf{C}$ & 0.01163 & 9.81 & 0.21 & 0.42 \\
\hline $\mathbf{D}$ & 0.01163 & 9.81 & 0.153 & 0.50 \\
\hline
\end{tabular}

The coefficient of discharge for the opening slots can be estimated from experiment observations and used in CFD. Figure 16 shows the depths of water fluctuations for different opening slots. When slot A was covered partially, the flow depths at each slot increased. As shown in Table 4, the orifice area plays more significant influence on the discharge than the depth of water. Although the depth of water increased above the partially covered opening slot $\mathrm{A}$, the discharge at slot $\mathrm{A}$ decreased. 


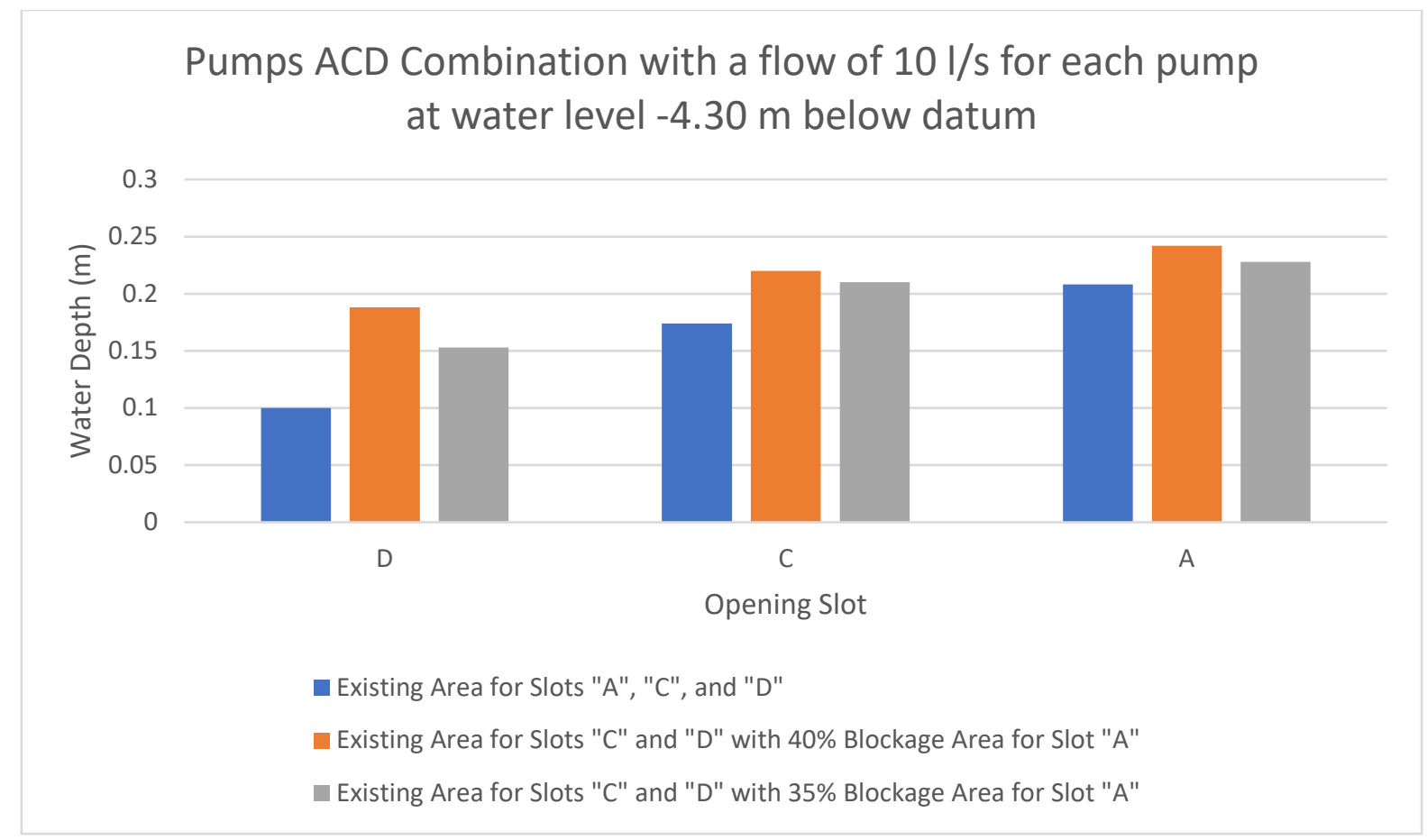

Figure 16. Depths of water fluctuations above the opening slots for the pumps ACD combination with a flow $10 \mathrm{l} / \mathrm{s}$ for each pump at a water level $-4.30 \mathrm{~m}$ under different conditions

\subsection{Pump Combination ABD}

For the pump combination ABD experiments, the area of Opening A was maintained at 35\% blockage while the area of Opening B was blocked in order to achieve the same water level in both tanks. The experimental results show that $45 \%$ and $35 \%$ coverage of Opening B and A could achieve the same water level in both tanks. The discharge coefficient of each slot opening was then estimated.

\subsubsection{The Procedure of Finding the Required Size of Opening B}

At a flow of $10 \mathrm{l} / \mathrm{s}$ for each pump and a water level of $-4.30 \mathrm{~m}$, this set of experiments was to determine the proper size for Opening B (with 35\% blockage of Opening A) that achieved the 
same water level in both tanks. In the beginning of experiments, the measured head difference was $144 \mathrm{~mm}$ and then the water level in the chamber above each slot was measured.

By maintaining 35\% blockage of Opening A, Opening B was blocked gradually to achieve the same water level at -4.30 in both tanks. The experiment was done for blockages of 35\%, 38\%, $40 \%$, and $45 \%$. Results show that a $45 \%$ blockage of Opening B could maintain an even water distribution in the chamber. Table 5 shows the experimental measurements for the ABD pumps combination with a flow of $10 \mathrm{l} / \mathrm{s}$.

Table 5. Experimental measurements of the pump ABD combination at a flow $10 \mathrm{l} / \mathrm{s}$ for each pump

\begin{tabular}{|c|c|c|c|}
\hline $\begin{array}{c}\text { Slot } \\
\text { Opening }\end{array}$ & $\begin{array}{c}\text { Percentage of } \\
\text { Opening } \\
\text { Blocked }\end{array}$ & $\begin{array}{c}\text { Area of Opening } \\
\left.\mathbf{( m}^{\mathbf{2}}\right)\end{array}$ & $\begin{array}{c}\text { Depth of Water Measured from the } \\
\text { Center of Opening (m) }\end{array}$ \\
\hline A & 0 & 0.01163 & 0.21 \\
\hline B & 0 & 0.01163 & 0.203 \\
\hline D & 0 & 0.01163 & 0.12 \\
\hline Head water difference between two tanks: $\mathbf{1 4 4} \mathbf{~ m m}$ & \\
\hline
\end{tabular}

Table 6. Experimental measurements of the pump ABD combination by blocking $35 \%$ of Opening A and 35\% of Opening B at a flow of $10 \mathrm{l} / \mathrm{s}$ for each pump

\begin{tabular}{|c|c|c|c|}
\hline $\begin{array}{c}\text { Slot } \\
\text { Opening }\end{array}$ & $\begin{array}{c}\text { Percentage of } \\
\text { Opening } \\
\text { Blocked }\end{array}$ & $\begin{array}{c}\text { Area of Opening } \\
\left.\mathbf{( m}^{\mathbf{2}}\right)\end{array}$ & $\begin{array}{c}\text { Depth of Water Measured from the } \\
\text { Center of Opening (m) }\end{array}$ \\
\hline A & $35 \%$ & 0.00756 & 0.227 \\
\hline B & $35 \%$ & 0.00756 & 0.224 \\
\hline D & 0 & 0.01163 & 0.163 \\
\hline \multicolumn{2}{|l}{ Head water difference between two tanks: $\mathbf{2 5} \mathbf{~ m m}$} \\
\hline
\end{tabular}


Table 7. Experimental measurements of the pump ABD combination by blocking $35 \%$ of Opening A and 38\% of Opening B at a flow of $10 \mathrm{l} / \mathrm{s}$ for each pump

\begin{tabular}{|c|c|c|c|}
\hline $\begin{array}{c}\text { Slot } \\
\text { Opening }\end{array}$ & $\begin{array}{c}\text { Percentage of } \\
\text { Opening } \\
\text { Covered }\end{array}$ & $\begin{array}{c}\text { Area of Opening } \\
\left.\mathbf{( m}^{\mathbf{2}}\right)\end{array}$ & $\begin{array}{c}\text { Depth of Water Measured from the } \\
\text { Center of Opening (m) }\end{array}$ \\
\hline A & $35 \%$ & 0.00756 & 0.235 \\
\hline B & $38 \%$ & 0.00721 & 0.228 \\
\hline D & 0 & 0.01163 & 0.173 \\
\hline \multicolumn{2}{|r|}{ Head water difference between two tanks: $\mathbf{1 1} \mathbf{~ m m}$} & \\
\hline
\end{tabular}

Table 8. Experimental measurements of the pumps ABD combination by blocking $35 \%$ of Opening A and $40 \%$ of Opening B at a flow of $10 \mathrm{l} / \mathrm{s}$ for each pump

\begin{tabular}{|c|c|c|c|}
\hline $\begin{array}{c}\text { Slot } \\
\text { Opening }\end{array}$ & $\begin{array}{c}\text { Percentage of } \\
\text { Opening } \\
\text { Covered }\end{array}$ & $\begin{array}{c}\text { Area of Opening } \\
\mathbf{( m}^{\mathbf{2}}\end{array}$ & $\begin{array}{c}\text { Depth of Water Measured from the } \\
\text { Center of Opening (m) }\end{array}$ \\
\hline A & $35 \%$ & 0.00756 & 0.235 \\
\hline B & $40 \%$ & 0.00698 & 0.23 \\
\hline D & 0 & 0.01163 & 0.18 \\
\hline
\end{tabular}

Table 9. Experimental measurements of the pumps ABD combination by blocking $35 \%$ of Opening A and 45\% of Opening B at a flow of $10 \mathrm{l} / \mathrm{s}$ for each pump

\begin{tabular}{|c|c|c|c|}
\hline $\begin{array}{c}\text { Slot } \\
\text { Opening }\end{array}$ & $\begin{array}{c}\text { Percentage of } \\
\text { Opening } \\
\text { Covered }\end{array}$ & $\begin{array}{c}\text { Area of Opening } \\
\left.\mathbf{( m}^{\mathbf{2}}\right)\end{array}$ & $\begin{array}{c}\text { Depth of Water Measured from the } \\
\text { Center of Opening (m) }\end{array}$ \\
\hline A & $35 \%$ & 0.00756 & 0.242 \\
\hline B & $45 \%$ & 0.00639 & 0.239 \\
\hline D & 0 & 0.01163 & 0.188 \\
\hline \multicolumn{2}{|r|}{ Head water difference between two tanks: $\mathbf{0 ~} \mathbf{~ m m}$} & \\
\hline
\end{tabular}


Figure 17 shows the measured water levels in the wet well for the pump combination ABD with a flow of $10 \mathrm{l} / \mathrm{s}$ for each pump. The water levels were in the same level $(-4.30 \mathrm{~m})$ when $35 \%$ and $45 \%$ of slot A and slot B were covered respectively.
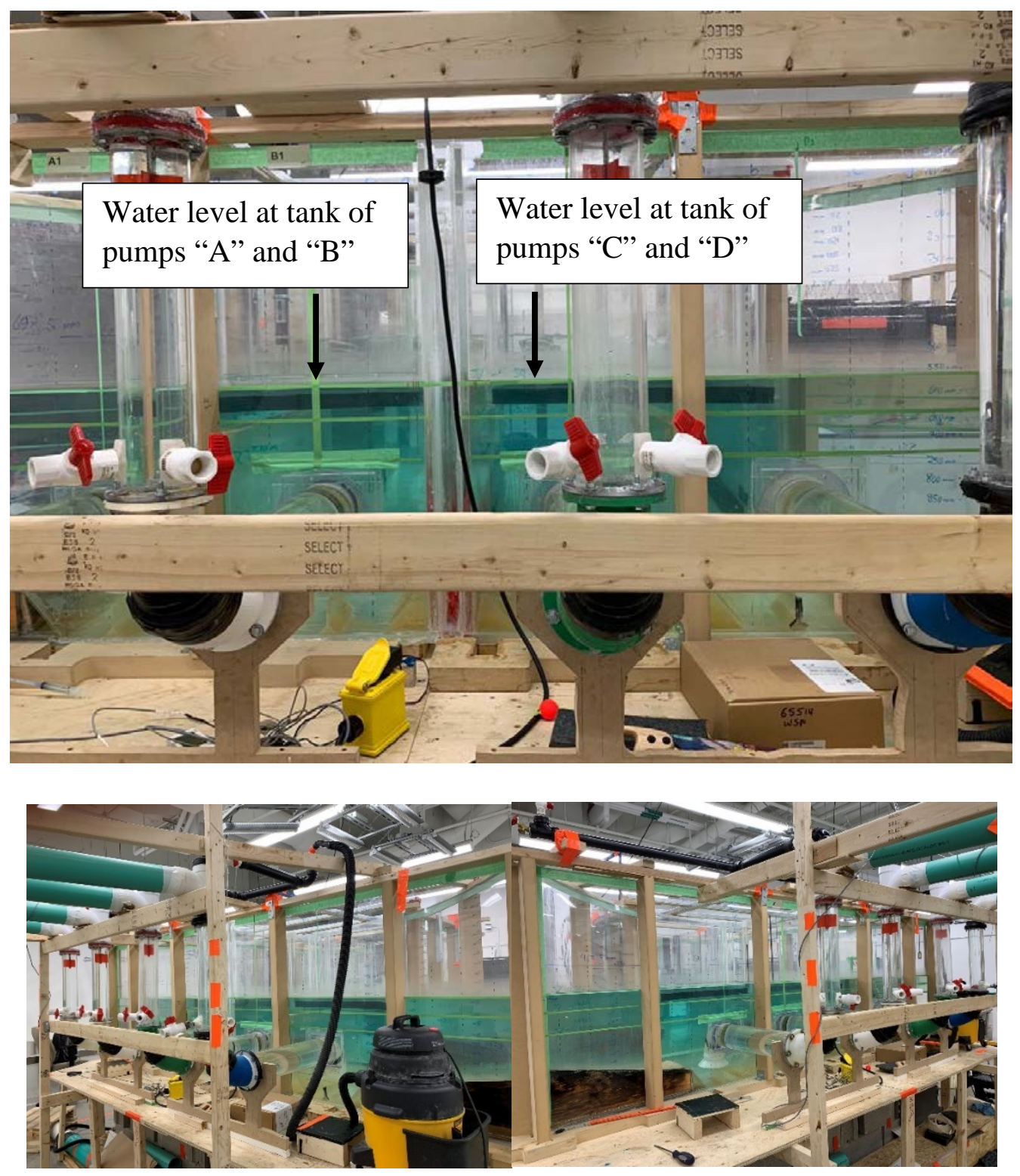

Figure 17. Water level in the both tanks with pumps ABD combination with a flow of $10 \mathrm{l} / \mathrm{s}$ for each pump by blocking $35 \%$ area of Opening A and $45 \%$ area of Opening B 
Figure 18 shows the hydraulic condition of the inlet pipe for the pump ABD combination with a flow of $10 \mathrm{l} / \mathrm{s}$ for each pump. The pipe was noticeably not full under all pumping conditions.

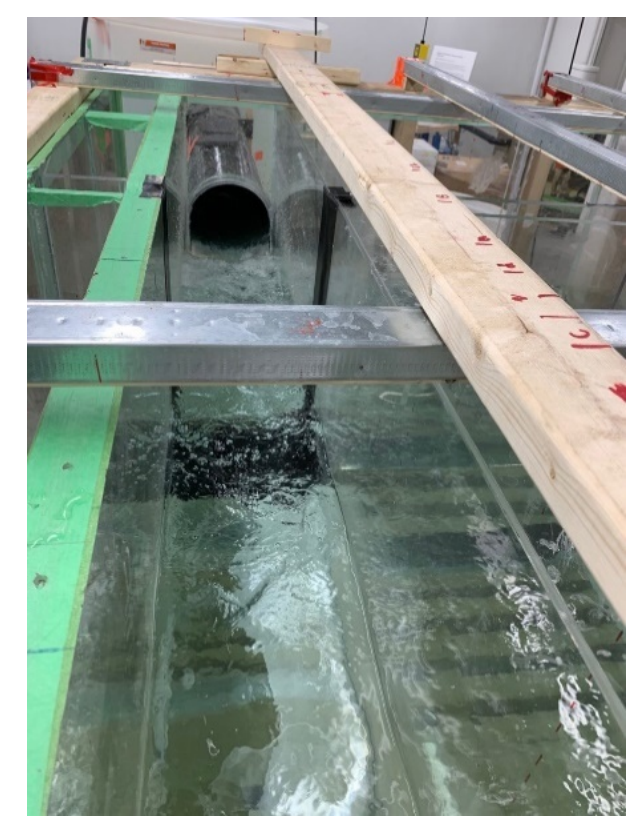

Figure 18. Inlet pipe flow conditions for the pump ABD combination with a flow 10 $\mathrm{l} / \mathrm{s}$ for each pump by blocking $35 \%$ of Opening A and $45 \%$ of Opening B

Figure 19 shows the opening slots in the chamber of the wet well for the pump ABD combination with a flow of $10 \mathrm{l} / \mathrm{s}$ for each pump.

The orifices flow equation (slot as an orifice) was applied to find the coefficient of discharge for the opening slots. Table 10 shows the estimated coefficient of discharge for Openings $\mathrm{A}, \mathrm{B}$, and $\mathrm{D}$ for the pump ABD combination with a flow $10 \mathrm{l} / \mathrm{s}$ for each pump by blocking $35 \%$ of Opening A and $45 \%$ of Opening B.

The coefficient of discharge for opening slots can be estimated from experiments and used in CFD. Figure 20 shows the depths of water fluctuations for opening slots. As shown in Table 10, the orifice area plays more significant influence on the discharge than the depth of water. Although the depth of water increased above the opening slots A and B, the discharge of slots A and B decreased. 


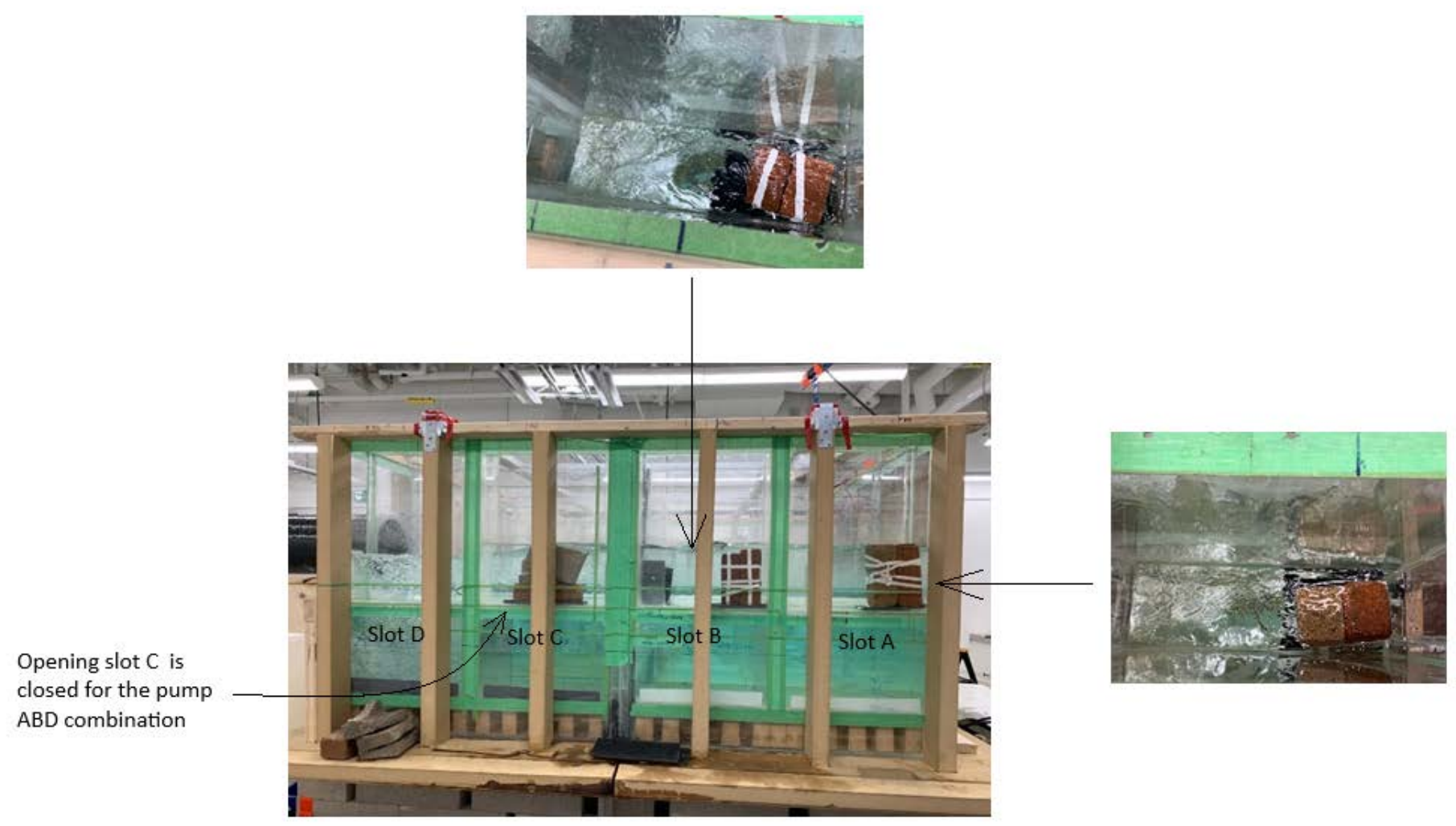

Figure 19. Opening slots for the pump ABD combination with a flow of $10 \mathrm{l} / \mathrm{s}$ for each pump by blocking 35\% of Opening A and 45\% of Opening B

Table 10. Estimation of coefficient of discharge for Openings A, B, and D for the pump ABD combination at a flow of $10 \mathrm{l} / \mathrm{s}$ with Opening A covered by 35\% and Opening B covered by $45 \%$

\begin{tabular}{|c|c|c|c|c|}
\hline Opening & $\begin{array}{c}\text { Area of opening } \\
\mathbf{( m}^{\mathbf{2}}\end{array}$ & $\begin{array}{c}\mathbf{g} \\
\mathbf{( m / \mathbf { s } ^ { 2 } )}\end{array}$ & $\begin{array}{c}\text { Depth of water } \\
\text { above the slot } \\
\mathbf{( m )}\end{array}$ & $\begin{array}{c}\text { Estimated Coefficient of } \\
\left.\text { discharge } \mathbf{( C}=\mathbf{Q} / \mathbf{A}^{*} \sqrt{ } \mathbf{2} \mathbf{g h}\right)\end{array}$ \\
\hline A & 0.00756 & 9.81 & 0.242 & 0.61 \\
\hline B & 0.00640 & 9.81 & 0.239 & 0.72 \\
\hline D & 0.01163 & 9.81 & 0.188 & 0.45 \\
\hline
\end{tabular}




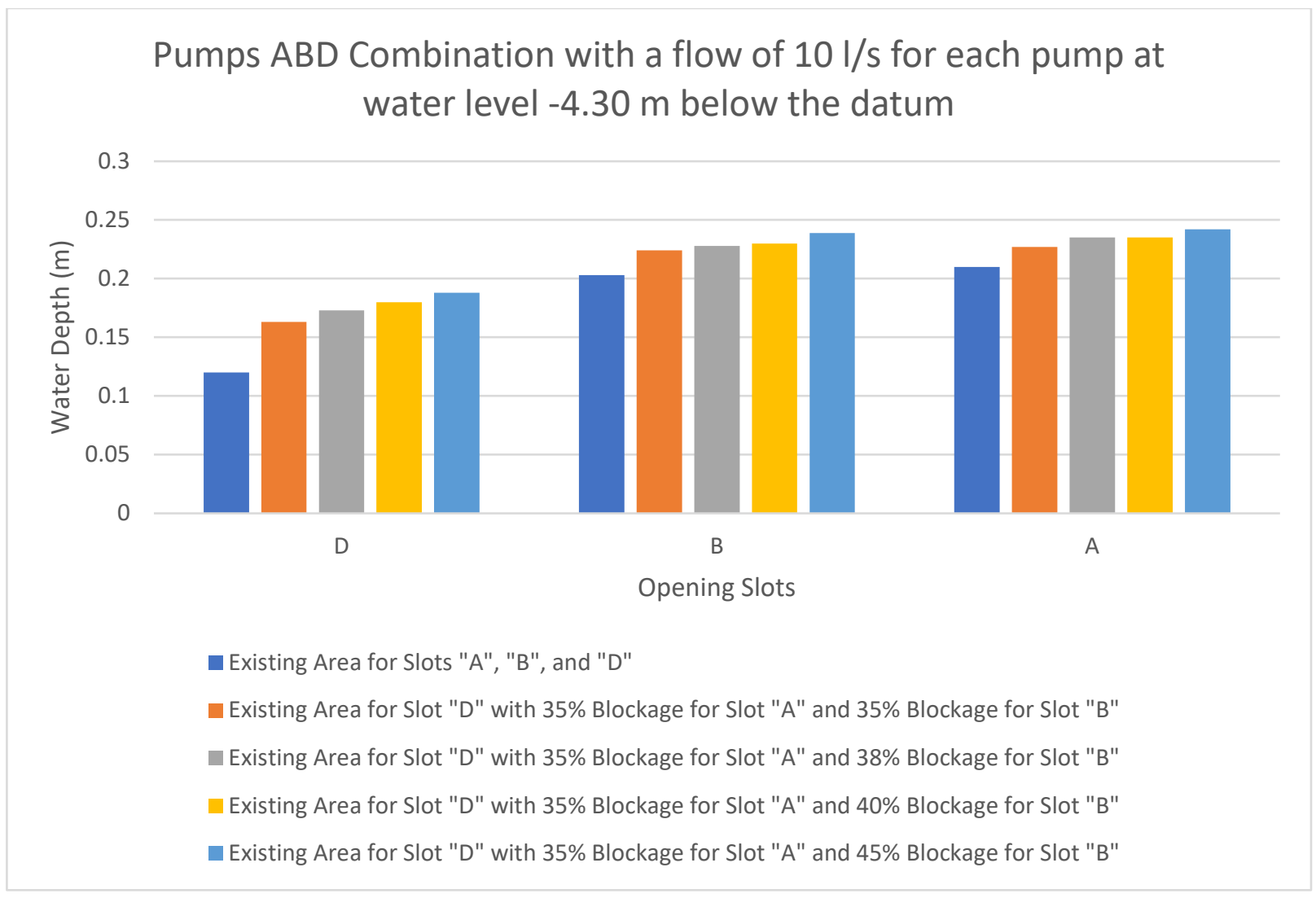

Figure 20. Depth of water fluctuations above the opening slots for the pump ABD combination with a flow $10 \mathrm{l} / \mathrm{s}$ for each pump at water level $-4.30 \mathrm{~m}$ in different conditions

Table 11 summarizes the estimated coefficient of discharge for Opening slots A and D, which had the constant area for the pump ACD and ABD combination with a flow of $10 \mathrm{l} / \mathrm{s}$ for each pump. The results show that the higher the water head the smaller the discharge coefficient.

Table 11. A summary of the estimated coefficient of discharge for opening slots A and D

\begin{tabular}{|c|c|c|}
\hline \multirow{2}{*}{ Opening } & Depth of Water (m) & Coefficient of Discharge \\
\hline \multirow{2}{*}{ A } & 0.228 & 0.63 \\
\cline { 2 - 3 } & 0.242 & 0.61 \\
\hline \multirow{2}{*}{ D } & 0.153 & 0.50 \\
\cline { 2 - 3 } & 0.188 & 0.45 \\
\hline
\end{tabular}




\subsection{Tapered Bell Design and Testing}

The tapered suction bell design alternative was fabricated and installed at Inlet Pump A (Fig. 21) which is the most critical area for vortex formation (i.e. The red area in Fig. 4 at Pump A).

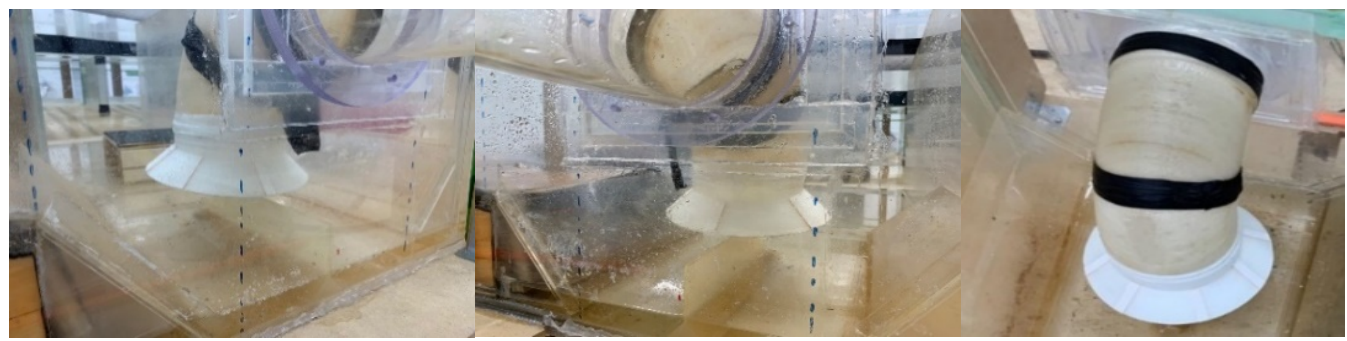

Figure 21. Tapered bell design installed on line A

\subsubsection{Pump A Working Under the Low Flow Condition}

As shown by the blue dye in Figure 22, water moves straightly into the suction bell at the lateral and front sides of the tapered bell inlet. No vortices were observed during the experiment.

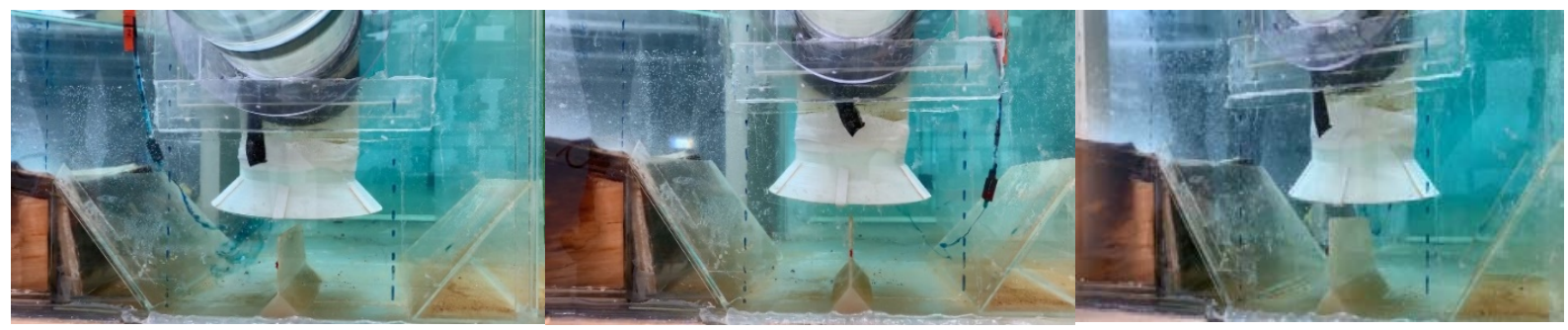

Figure 22. Dye injection at lateral and front sides of the tapered bell under low flow condition

Figure 23 depicts the blue dye injection at the back side near the wall. The video record showed that there was mild water rotation at the back side of the tapered bell near the wall. As a result, the pump operation may not be seriously impacted. 


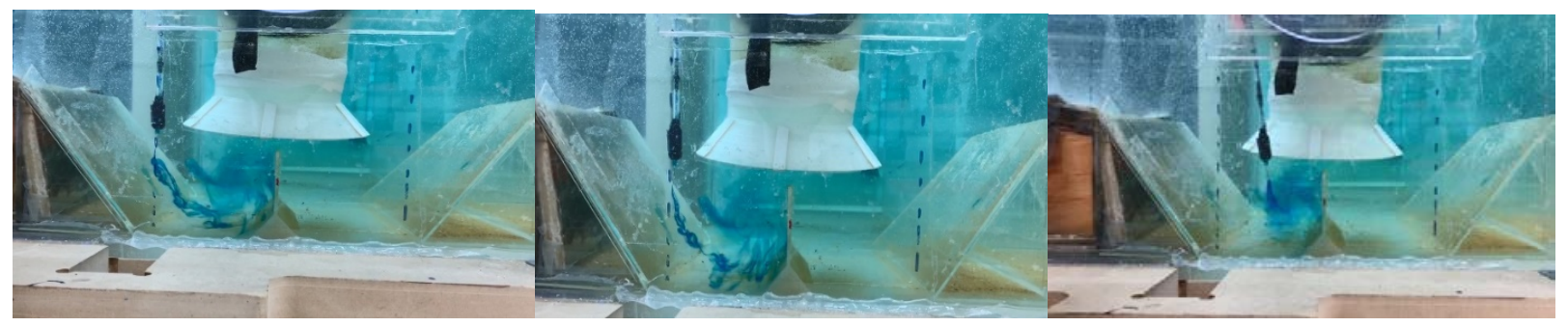
(a) Time $=5 \mathrm{sec}$
(b) $=10 \mathrm{sec}$
(c) $=15 \mathrm{sec}$

Figure 23. Dye injection at the back side of the tapered bell inlet showing water rotation under low flow condition

\subsubsection{Pump A Working Under the Cleaning Cycle Scenario}

As shown by the blue dye in Figure 24, water moves straightly into the suction bell at the lateral and front sides of the tapered design bell inlet. No vortices were observed during experiment.

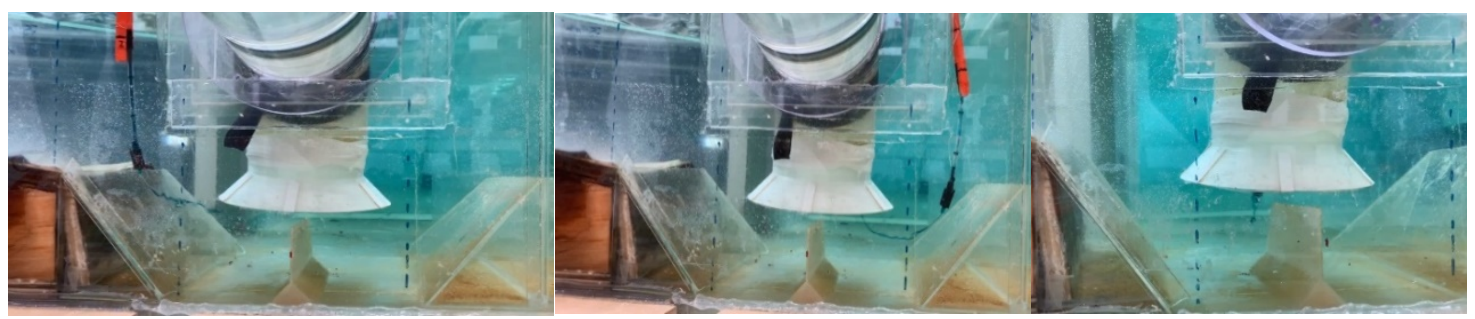

Figure 24. Dye injection at lateral and front sides of the tapered bell under cleaning cycle scenario

Figure 25 depicts the blue dye injection at the back side near the wall. The video record showed that there was mild water rotation at the back side of the tapered design bell near the wall. As a result, the pump operation may not be seriously impacted.

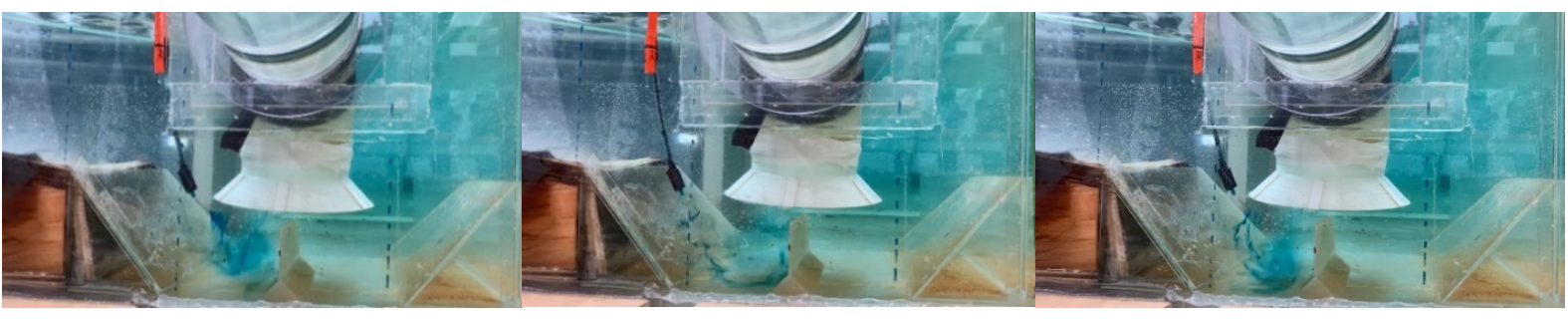

(a) Time $=5 \mathrm{sec}$

(b) Time $=10 \mathrm{sec}$

(c) Time $=15 \mathrm{sec}$

Figure 25. Dye injection at the back side of the tapered bell inlet showing water rotation under cleaning cycle scenario 


\section{Chapter 6.}

\section{Conclusions and Recommendations}

\subsection{Conclusions}

Large scale hydraulic pumping stations with one or more pumps have been broadly used by municipal wastewater services to move sewage to wastewater treatment plants. When flow swirls around the suction bell of the sewage pump intake, free-surface and sub-surface vortices may be formed, resulting in poor pump operation. The perfect flow condition entering the pump intake should be uniform, steady, and without direct entrainment of air by free-surface vortices. Physical and numerical models are typically used to analyze the flow condition entering the suction bell and travelling through the pump column of the pump intake and determine the best design which alleviates the associated hydraulic problems.

In cooperation with WSP Canada Ltd., a scale/physical modelling study of the First Narrows Sewage Pumping Station was conducted by the Ryerson research team at Ryerson University Centre of Urban Innovation's laboratory. Based on the ANSI/Hydraulic Institute (HI) standard 9.8 for Pump Intake Design (2018), the physical model testing focused on flow of the approach channel and vortex formation at the bell shape entrance of the intake. Based on the witness testing observation of any possible vortex formation, this physical model study has established the appropriate openings for the flow to enter the wet well and the practical inlet shape (e.g. a tapered shape versus a bell one).

By considering the Froude similitude and a safety factor of 2 in the calculations of Reynolds number and Weber number for the bell inlet, a scale of 1:4.5 was used for the physical model, meeting all the requirements in HI standard. In addition, the space at the Ryerson University's Centre of Urban Innovation Laboratory was appropriate for the physical model construction. Part of the scale model was constructed using clear plastic in order to allow observation of flow condition and potential vortex formation at critical areas. 
Analyses of the experimental results show that by blocking 35\% of opening A and 45\% of Opening B for the pump ACD and ABD combinations with a flow of $10 \mathrm{l} / \mathrm{s}$ for each pump, the water levels at both tanks of the wet well were almost equal at $-4.30 \mathrm{~m}$ below the datum. It can be concluded that these percentages of blockages will result in uniform flow conditions in the approach channel. The higher the water head above the openings the smaller the calibrated discharge coefficient. In addition, the orifice diameter of the openings plays more significant influence on the discharge coefficient than that of the water head. The experimentally calibrated discharge coefficients of the opening slots can be used in CFD.

No vortices were observed at the lateral and front sides of the tapered bell inlet under the low flow condition and the cleaning cycle scenario. However, there was mild water rotation at the back side of the tapered bell near the wall. From these observations, it can be concluded that the pump operation may not be seriously impacted by this tapered bell inlet design.

\subsection{Recommendations}

Based on the experimental investigation in this study, it is recommended that future works be focused on

- The physical modelling of the low flow condition at a higher water level $(-5.10 \mathrm{~m})$. A larger intake submergence (i.e. $-4.9 \mathrm{~m}$ ) will have less chance for vortex formation. In addition, higher water level removes the gap between the chamber and surface of wastewater in the wet well which may cause odor problems.

- The design of the tapered bell inlet can be further refined in order to achieve a uniform flow through the suction pipe. 
Appendix 


\section{Appendix A}

\section{Appendix A. Scale Calculations}

\begin{tabular}{|c|c|c|c|c|c|c|c|c|c|c|c|}
\hline \multicolumn{4}{|c|}{ Physical Model } & \multicolumn{6}{|c|}{ Prototype } & \multirow{4}{*}{$\begin{array}{c}\text { SCALE } \\
\text { Lr }\end{array}$} & \\
\hline \multicolumn{2}{|c|}{ US Customary } & \multicolumn{2}{|r|}{ SI Metric } & \multicolumn{2}{|c|}{ US Customary } & \multirow[b]{3}{*}{ Pipe Class } & \multicolumn{3}{|c|}{ SI Metric } & & \\
\hline$O D$ & $t$ & ID & ID & $O D$ & $t$ & & $O D$ & $\mathrm{t}$ & ID & & \\
\hline in. & in. & in. & $\mathrm{mm}$ & in & in & & $\mathrm{mm}$ & $\mathrm{mm}$ & $\mathrm{mm}$ & & \\
\hline & & 10.6 & 270.1 & & & & 1200 & & 1200.0 & 4.44318 & \\
\hline 3.75 & 0.125 & 3.489 & 88.62 & 16 & 0.25 & $\mathrm{SCH} 10 \mathrm{~S}$ & 393.8 - & & 393.8 & 4.44318 & Pump Inlet (rise \\
\hline 5.50 & 0.125 & 5.289 & 134.34 & 24 & 0.25 & $\mathrm{SCH} 10 \mathrm{~S}$ & 609.6 & 6.35 & 596.9 & 4.44318 & Pipe \\
\hline 8.24 & 0.125 & 7.990 & 202.9 & 36 & 0.25 & $\mathrm{SCH} 10 \mathrm{~S}$ & 914.4 & 6.35 & 901.7 & 4.44313 & Bell (Custom) \\
\hline
\end{tabular}

$\begin{array}{rrrlrrrr} & \text { MLD } & \text { L/s } & \text { L/s } & & 1 & 2 & 3 \\ \text { Firm Flow } & 110.00 & 1273.15 & & \text { Total Flow (L/s): } & 424.382716 & 848.7654321 & 1273.15\end{array}$ Flow per Pump $\quad 36.67 \quad 424.38 \quad 650.00$

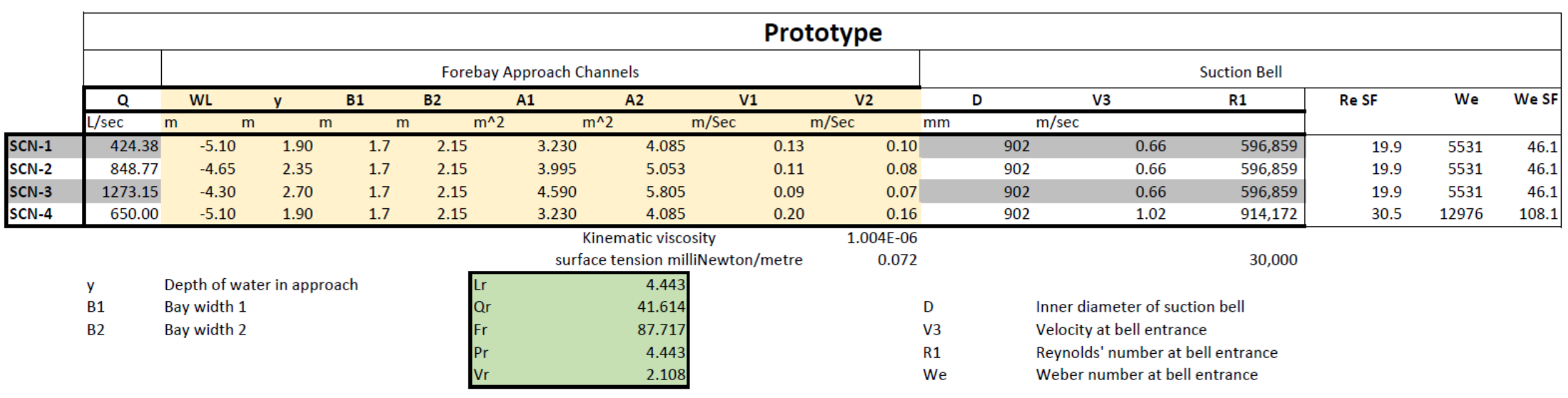

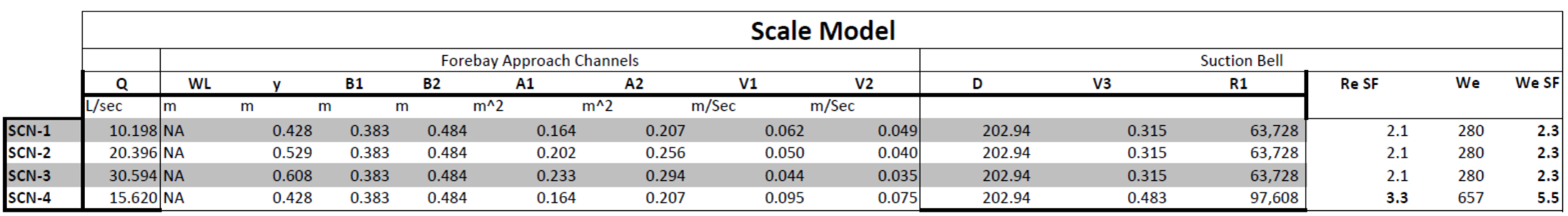




\section{References}

1) Li, S., Lai, Y., Weber, L., Silva, J. M., \& Patel, V. C. (2004). Validation of a threedimensional numerical model for water-pump intakes / Validation d'un modèle numérique tridimensionnel pour les aspirateurs de pompes. Journal of Hydraulic Research, 42(3), 282-292. https://doi.org/10.1080/00221686.2004.9641196

2) Product, G. N., \& Two, R. (1966). Chapter $1:$ Introduction Chapter $1:$ Introduction, 1-16.

3) Rodriguez, I. D. (2003). N Umerical M Odel for the L Ateral, 125(July), 1119-1125.

4) Shore, N., Treatment, W., \& Conveyance, P. (2018). NORTH SHORE WASTEWATER TREATMENT PLANT CONVEYANCE PROJECT PHYSICAL ( SCALE ) MODELLING REPORT PHYSICAL ( SCALE ) MODELLING.

5) Tokyay, T. E., \& Constantinescu, S. G. (2006). Validation of a large-eddy simulation model to simulate flow in pump intakes of realistic geometry. Journal of Hydraulic Engineering, 132(12), 1303-1315. https://doi.org/10.1061/(ASCE)07339429(2006)132:12(1303) 